دراسة أثر بعض الطرق الإرشادية الزراعية كأحد المتغيرات المرتبطة بمشار كة الريفيات في إتخاذ القرارات التسويقية لبعض المنتجات النبانية والحيو انية في بعض قرى محافظتى البحيرة والغربية

ليلى أنور طلبة، صفاء أمد فهيم1

الإرشادية، ومصادر المعلومات، وعمر المبحوثة، والحيازة المزرعية

للمبحوثة، والحيازة الحيوانية للمبحوثة.

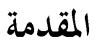

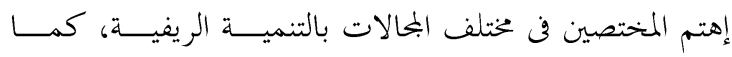

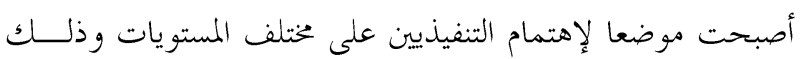

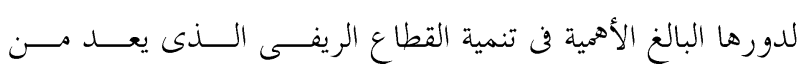

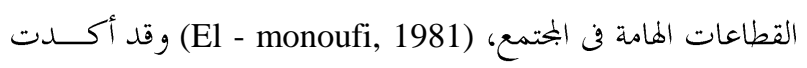
العديد من الدراسات والتجارب التنموية أن توافر رؤوس الأمــــوال و المو ارد الطبيعية ليست فقط الأساس لنجاح عملية التنمية، ذلك لأن

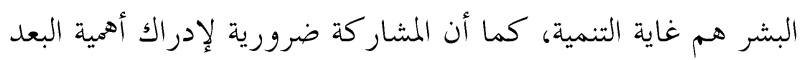

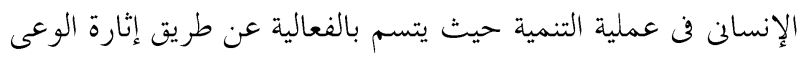

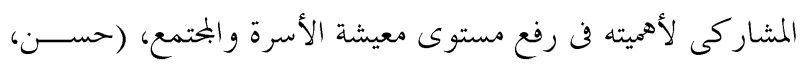

$$
\text { وآخرون، r... (r) }
$$

وقد أصبحت قضية التنمية اليوم هى حديث الساعة، و الشاغل

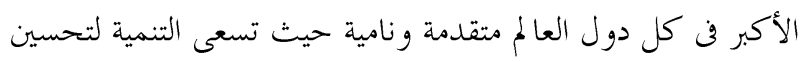
و تطوير الظروف المعيشية للسكان عن طريق تطوير الحياة الإقتصادية

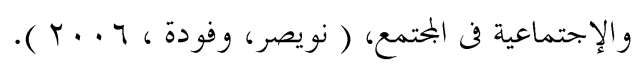
ولقد إتخذت العديد من الدول خطوات واسعة في بحال التنمية الريفية للنهوض بمستويات المعيشة للريفيين، وتضييق الفجـــوة بـــين سكان الريف والحضر من خلال النهوض بالعنصر البشرى باعتباره

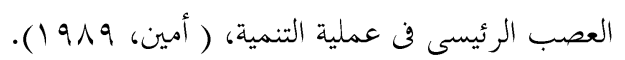

ومما لاشك فيه فإن تنمية مصر وفضتها وحضارها تقوم على

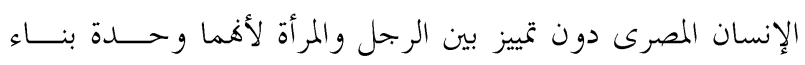

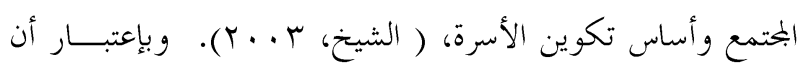

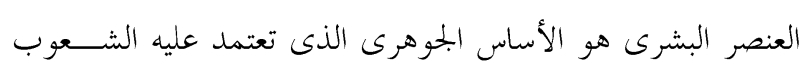

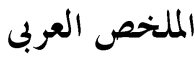

استهدف هذا البحث بصفة أساسية دراسة أثر بعــض الطـــرق

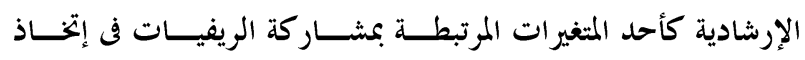

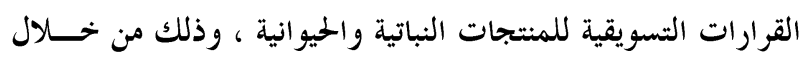

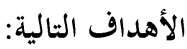

التعرف على بعض الخصائص المميزة للمبحوثات، والتعرف على

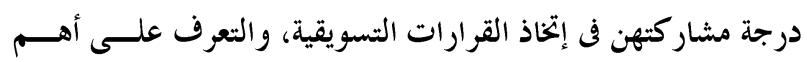

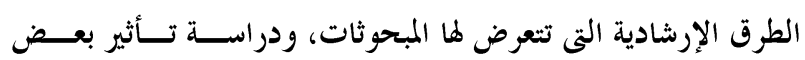

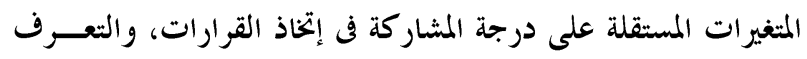

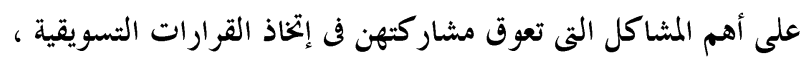

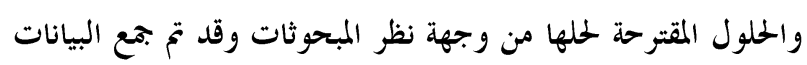

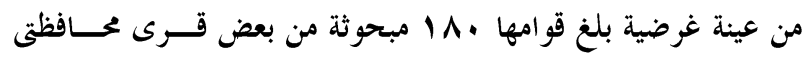

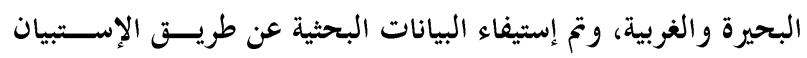
بالمقابلة الشخصية وأوضحت نتائج الدراسة مايلى: - -

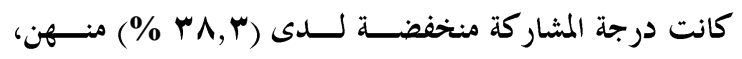

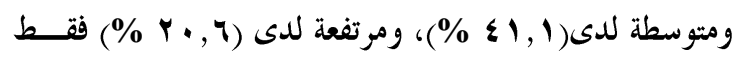
منهن. - تبين أن أهم الطرق الإرشادية التى تتعرض لها المبحوثات للحصول

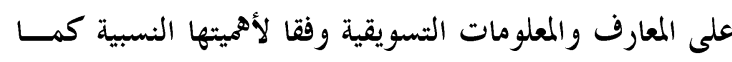

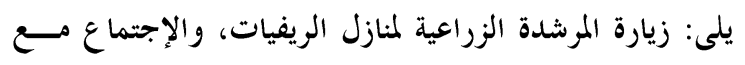

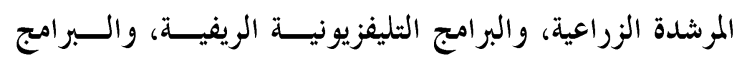

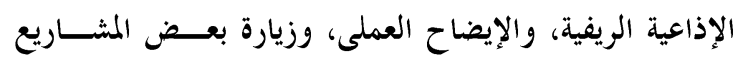
التنموية، و المطبوعات الإرشادية. - تبين وجود علاقة إنحدارية مغزوية بين المشاركة في إتخاذ القـــرارات

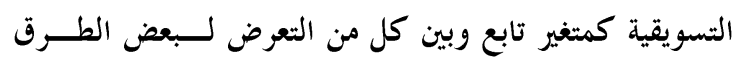




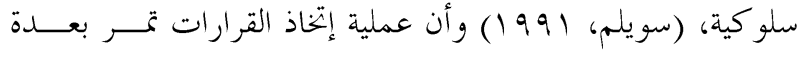

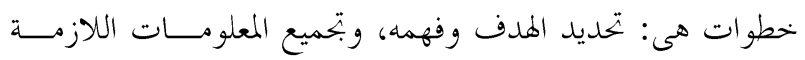

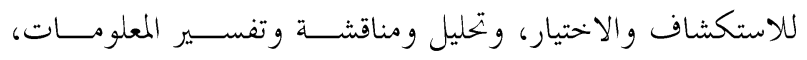

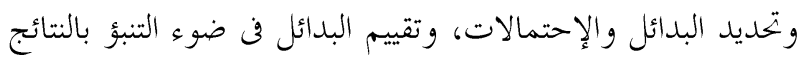

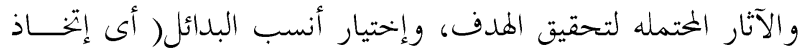

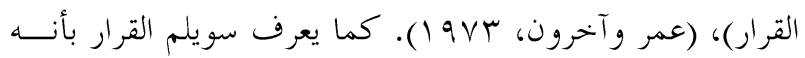

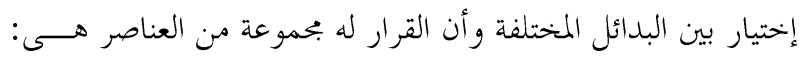

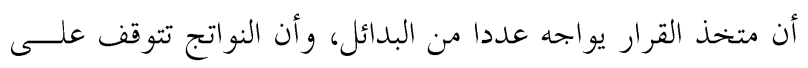

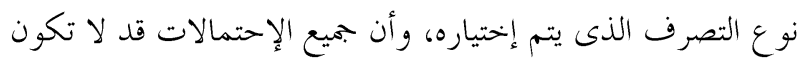

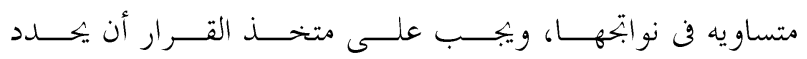

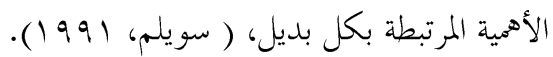
ومما لاشك فيه أن بناح الإرشاد الزراعى فن توصيل النتـائج

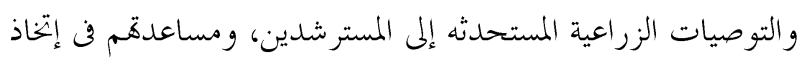
القرارات المزرعية السليمة، يتم من خلال الطرق الإرشادية المختلفة،

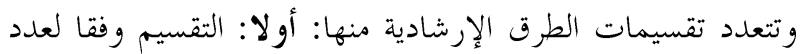

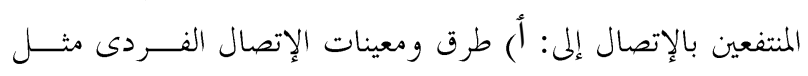

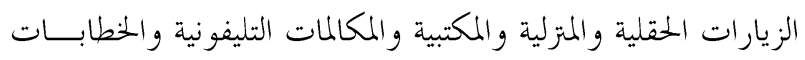

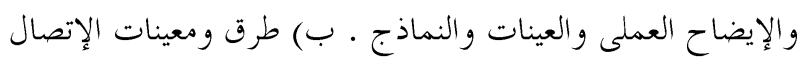
الجماعى مثل الإجتماعات و الرحلات والمحاضرات والإيضاح العملى لواتل بالممارسة والصور المتحر كة. ج) طرق ومعينات الإتصال الجماهيرى

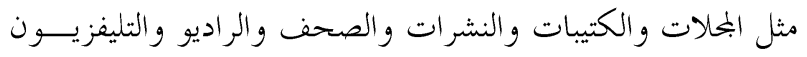

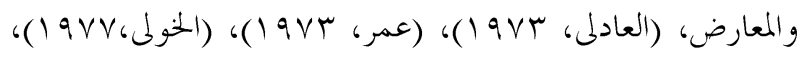

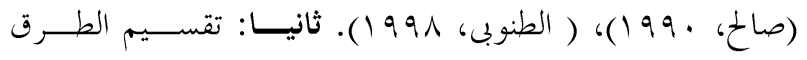

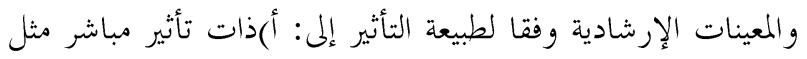

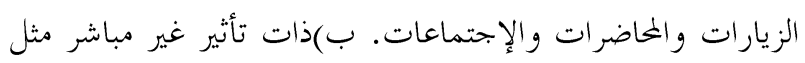

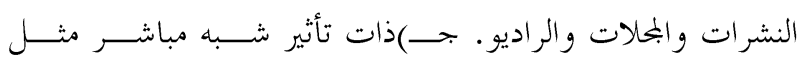

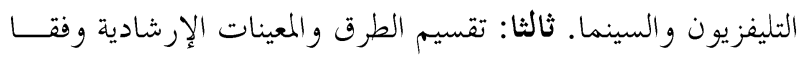
لطريقة عرض المعلومات ومعاملة الرسالة إلى : أ) كامية مثل الراديو و التليفزيون و السينما و الإجتماعات. ب)كتابية مثل الكتب و المحلات

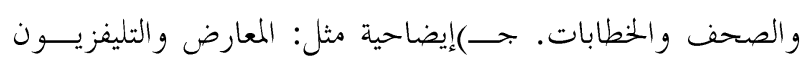
و الملصقات و الصور والأفلام وطرق الإيضاح بعرض النتائج. رابعا:

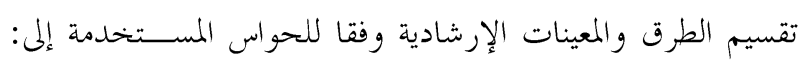

النامية في تحقيق الخطط التنموية المستهدفة، فإن الإستثمار الكامـلـ

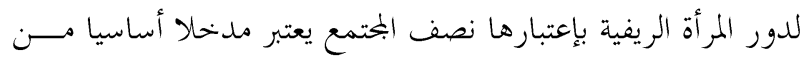

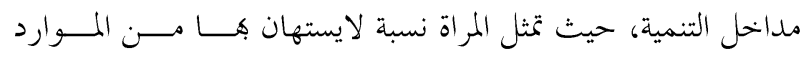

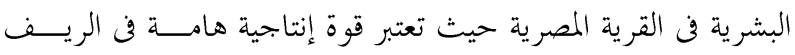

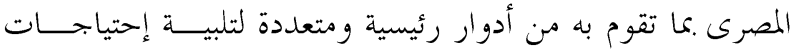

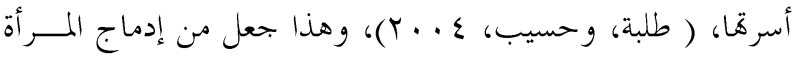

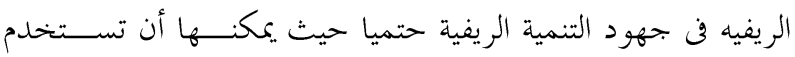

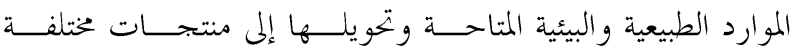

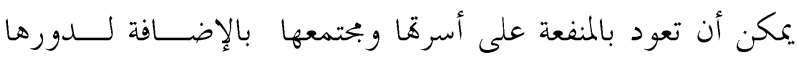

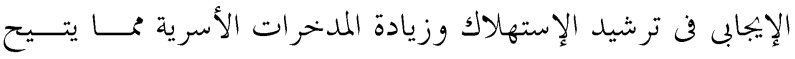

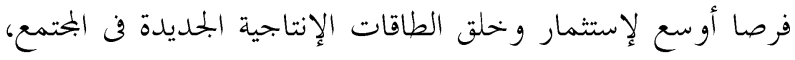
ولذلك كان من الضرورى الإهتمام بتثقيفها وتوعيتها وإعــــادها

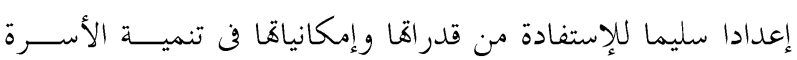

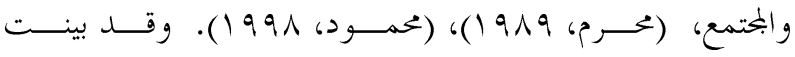

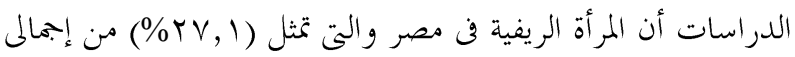

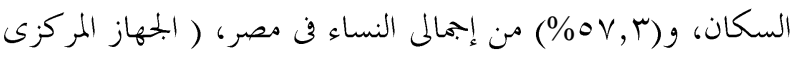

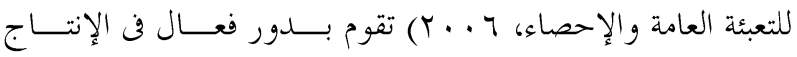

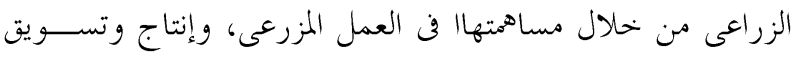
المنتجات الزراعية النباتية والحيوانية، وإدارة الموارد وصيانتها، وإتخاذ

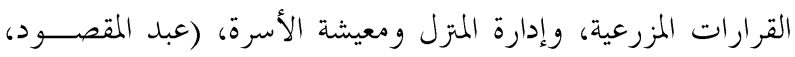

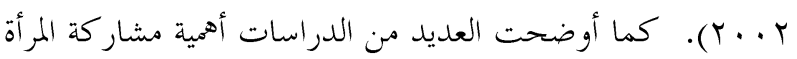

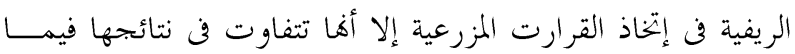

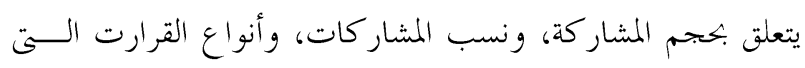

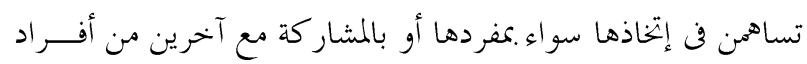

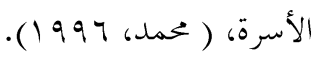
ومما لاشك فيه فإن بناح الإرشاد الزراعى في نقل وتوصسيل

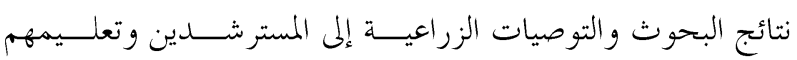

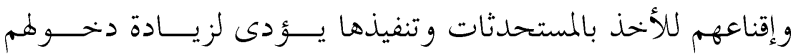
وإرتفاع مستو ياتم الإقتصادية والإجتماعية وتحقيق النهضة والرفاهية

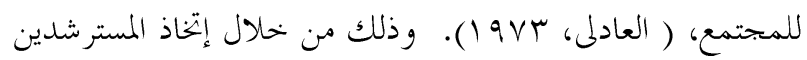
لقرارات تبنى الأفكار الجديدة، ولذا يرى بعض الكتاب أن الإرشاد ولاد

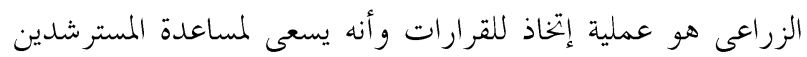

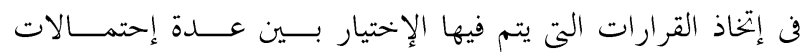




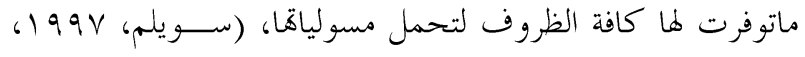

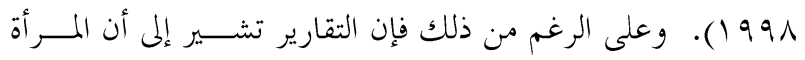

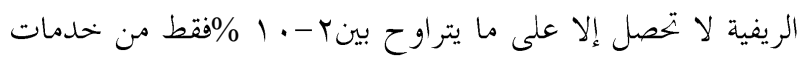

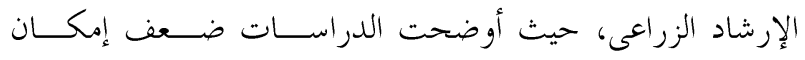

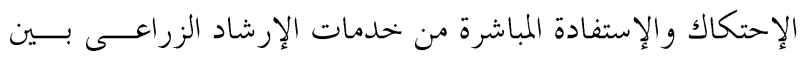

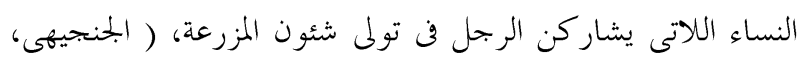

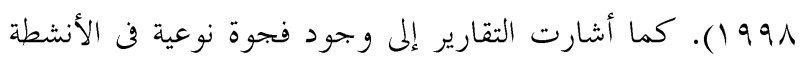

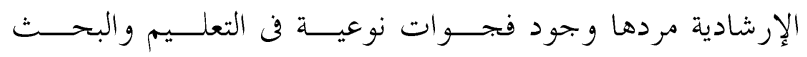

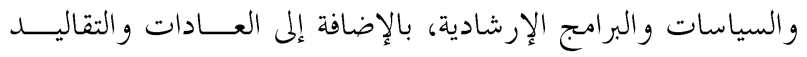

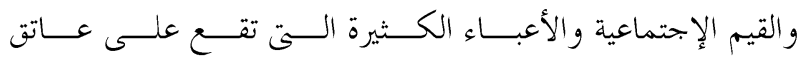
المرأة الريفية والتى تحد من مشاركتها في الأنشطة الإرشادية أو إتخاذ

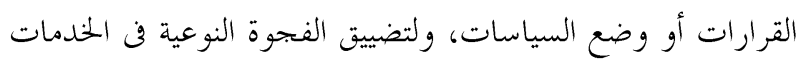

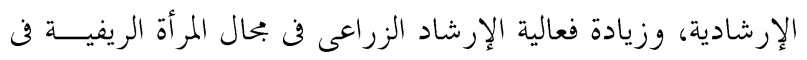

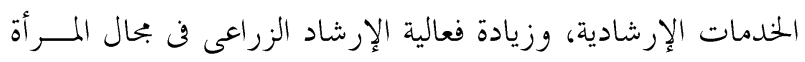

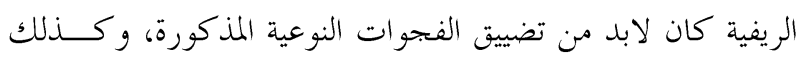

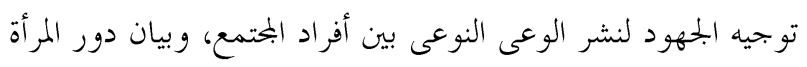

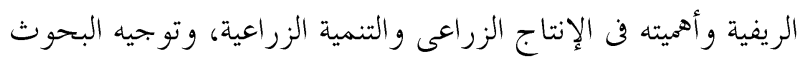
و السياسات بالشكل الذى يؤدى إلى معرفة إحتياجات المرأة الريفية وآرائها المختلفة، والعمل على إنتاج التكنولوجيا المناسبة ها والــتئي

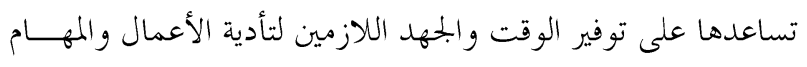

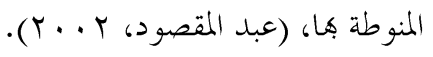

\section{المثكلة البحثية}

لاشك أن التوجهات الحميثة للإرشاد الزراعى في مصر نحسـو

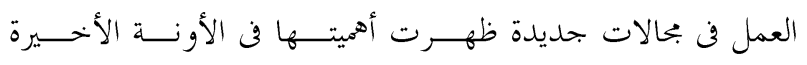

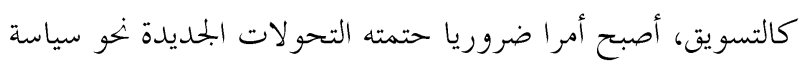

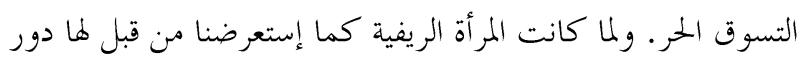
هام وحيوى في تسويق المنتجات الزراعية، وفى حين إهتمت العديد

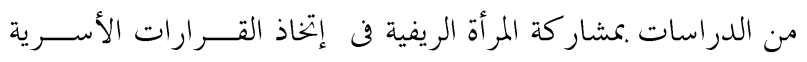

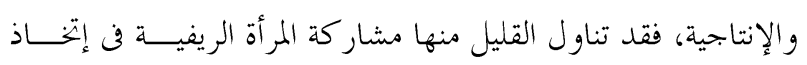

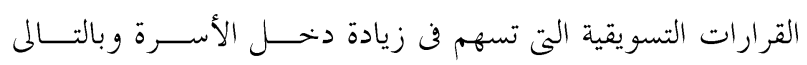

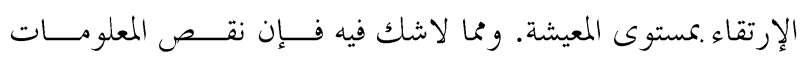

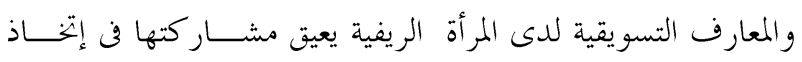

سمعية مثل الر اديو و التليفزيون والإجتماعــات. ب)بصــــية مثـلـل

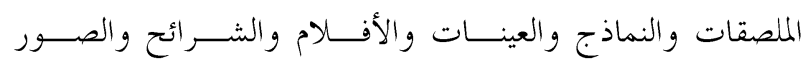

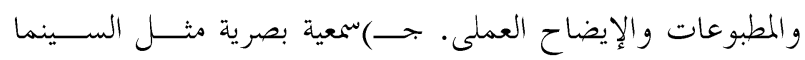

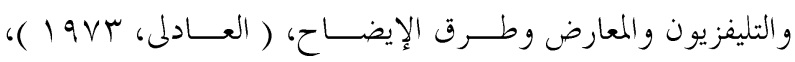
(199. • (1)

وقد أوضحت نتائج بعض الدراسات أهمية إختيــار أفضـل

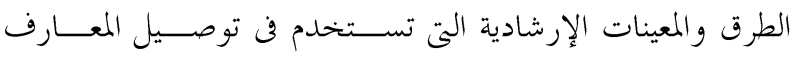
و المعلومات والمهارات المختلفة للريفيات، وقد بينت دراسة( السيد،

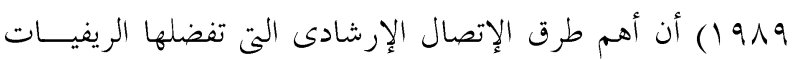

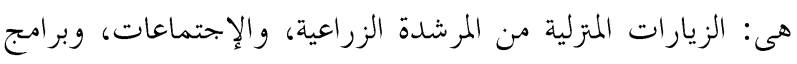

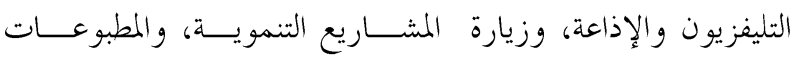

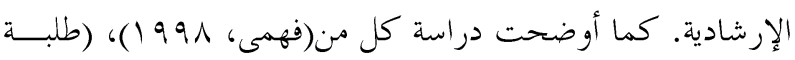

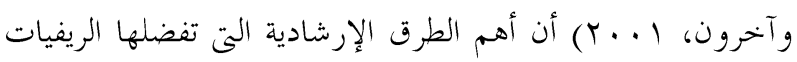

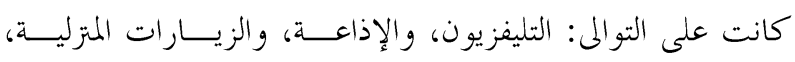
والإيضاح العملى، والنشرات الإرشادية ثم المطبوعات الإرشادية. كما بينت دراسة(طلبه وحسيب، ع . . ب) أن أهم الطرق الإرشادية

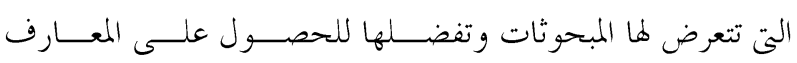

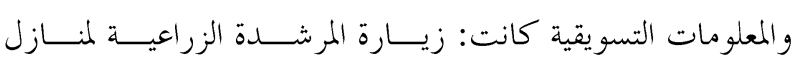

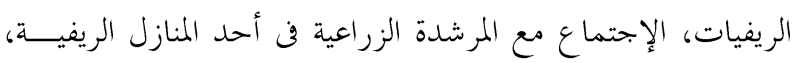

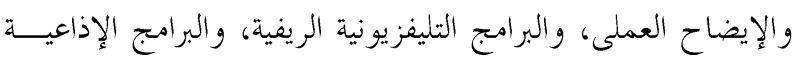
الريفية، وزيارة المشاريع التنموية، والمطبوعات الإرشادية. هذا وقد أكدت العديد من الدراسات تعاظم الدور الإقتصادى

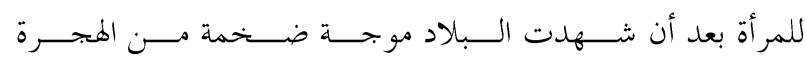

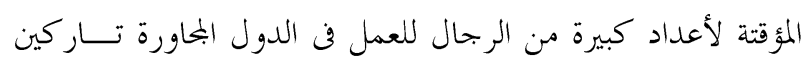

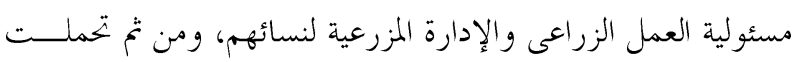

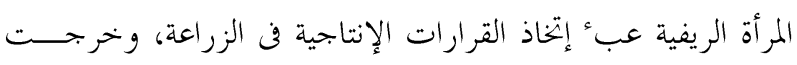
تتعامل مع مستلزمات الإنتاج وتسويق الحاصلات مظهرة كفــاءة

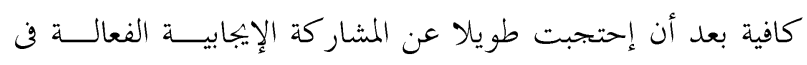
مواجهة البحتمع الريفى، (محرم، ع . . ب).

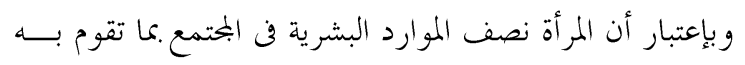

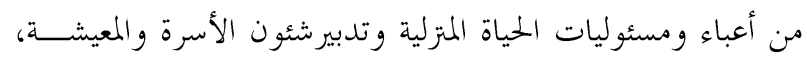

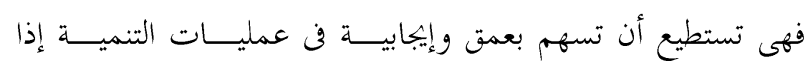




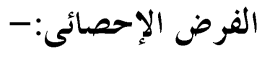

لتحقيق الفرض النظرى المتعلق بالهدف الرابــع، تم صــياغة

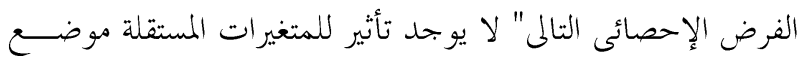

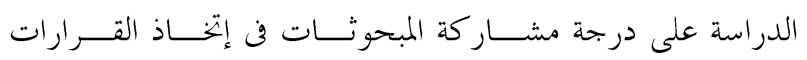

$$
\text { التسو يقية". }
$$

\section{الأسلوب البحثى}

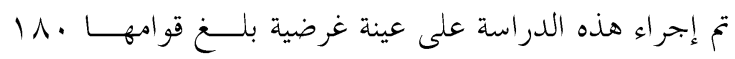
مبحوثة تم إختيارهن من بعض قرى محافظتي البحيرة والغربية، وقد تح مئم

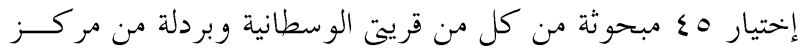

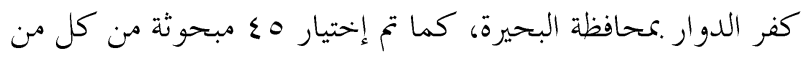

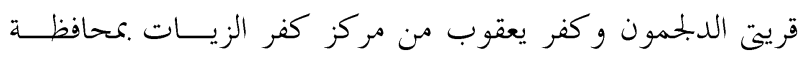

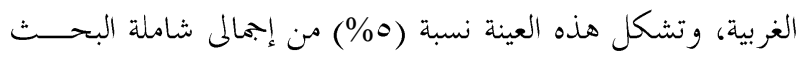

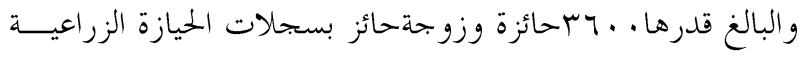
بالجمعيات الزراعية بقرى الدراسة الأربع. وقد تم إختيار المبحوثات

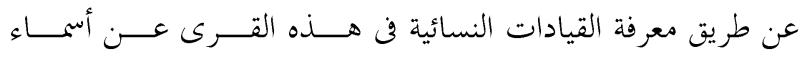

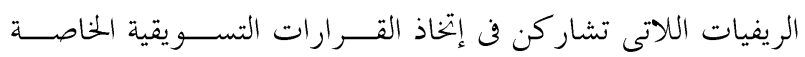

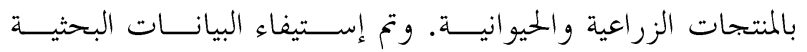

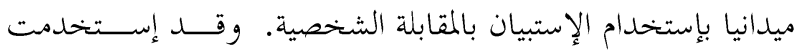

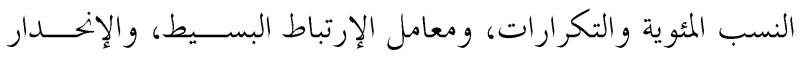

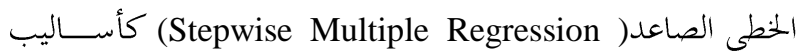

$$
\begin{array}{r}
\text { إلحصائية لعرض بيانات الدراسة. } \\
\text { التعريفات الإجر ائية }
\end{array}
$$

إتخاذ القرارات: تعرف عملية إتخاذ القرارات بأهنا عملية عقلانيــة Rational

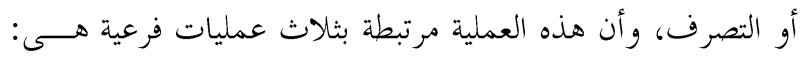

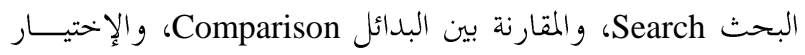
Selection

.$(199$.

ويقصد بعملية إتخاذ القرارات في هذه الدراسة الجهود التى تبذها

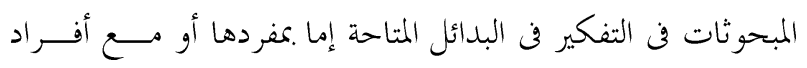

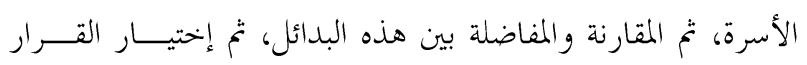

القرارات التسويقية الناجحة و المناسبة بما يؤثر على العائـــــ المــادى الذى يمكن أن تستفيد منه الأسرة، لذلك كان من الأهمية أن يقوم

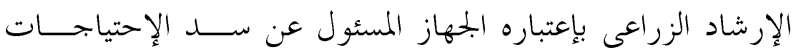
التعليمية والتدريبية لجمهور المسترشدين بتوفير المعارف والمعلومات

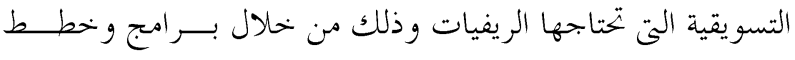
وسياسات تبنى على قاعدة سليمة من المعلومات الدقيقة وعن طريق

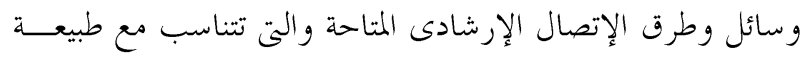

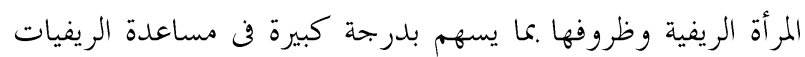
على إتخاذ القرارات التسويقية الناجحة فن الوقت المناسب. ولذا أهتمت هذه الدراسة بالتعرف على القرارات التســــيقية

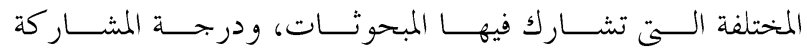

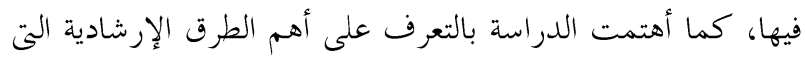

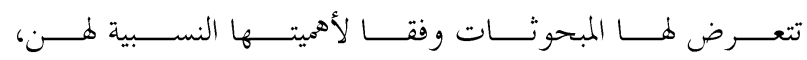

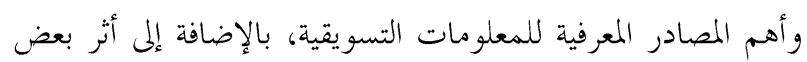

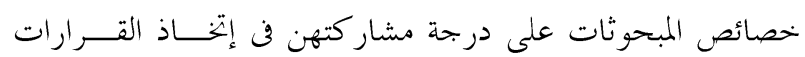
التسو يقية.

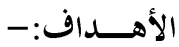

1- التعرف على أهم الخصائص المميزة للمبحوثات. r- التعرف على درجة مشاركة المبحوثات في إتخـــاذ القــــارات التسو يقية لبعض المنتجات الزراعية والحيو انية.

r- التعرف على أهم الطرق الإرشادية التي تتعرض لها المبحوثات، وأهم مصادر المعلومات.

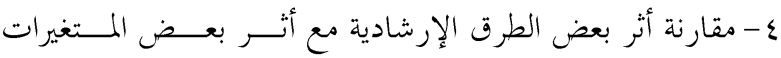

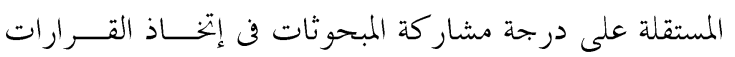

$$
\text { التسويقية. }
$$

هـ التعرف على أهم المشاكل التئ تعوق مشار كة المبحوثـــات فن

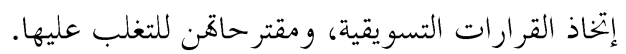

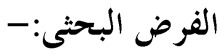

لتحقيق الهدف الرابع للدراسة، تم صياغة الفرض النظرى التالى:

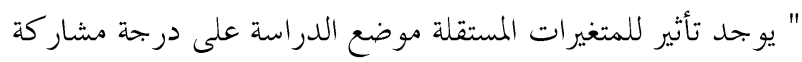
المبحوثات في إتخاذ القرارات التسويقية". 
- الحالة التعليمية للزوج: هى الإلمام بالقراءة والكتابة، والإنتقــال

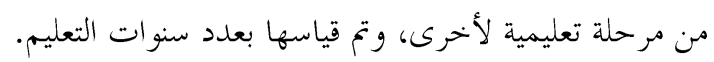
- مستوى معيشة الأسرة: هو بمموع القيم الرقمية التى حصــلت

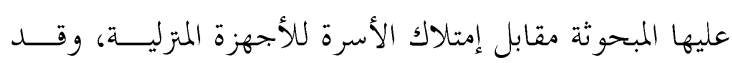
أعطيت درجة واحدة لملكية كل جهاز. - الإنفتاح الحضارى: هو بجموع القيم الرقمية التى حصلت عليها

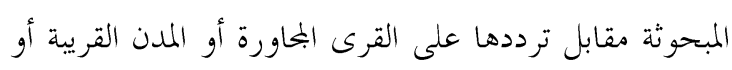
عاصمة المحافظة، وقد أعطيت الاستجابات( دائما، احيانــا،

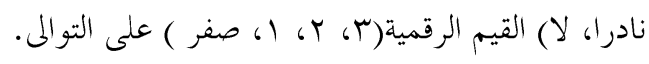

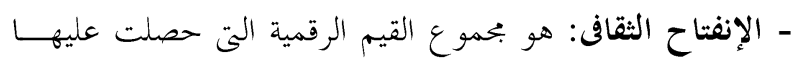

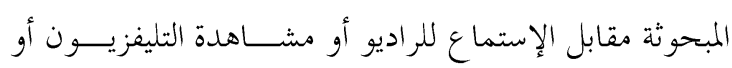

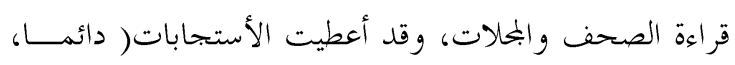

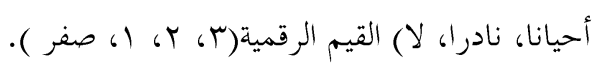

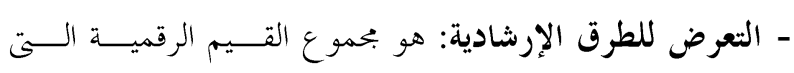

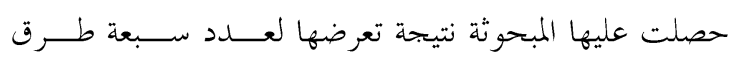

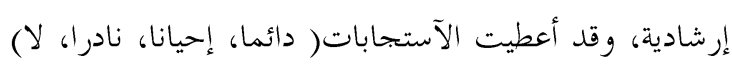

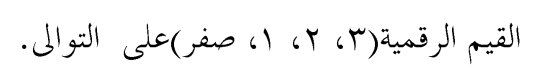
- التعرض لمصادر المعلومات: هى بحموع القــيم الرقميــة الــتى

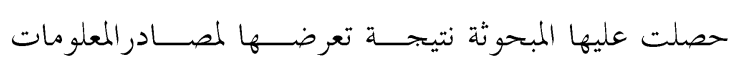

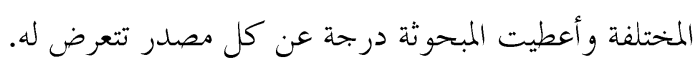

\section{النتائج ومناقشتها}

\section{أولا: الحُصائص المميزة للمبحوثات:}

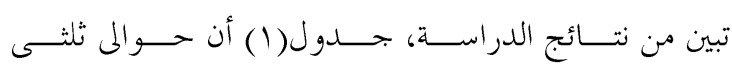

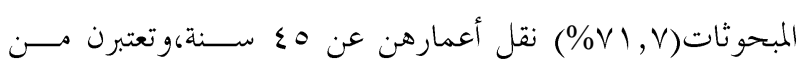

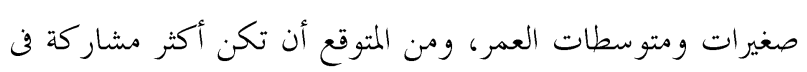

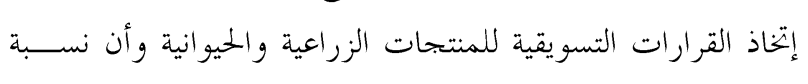

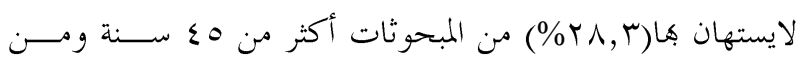

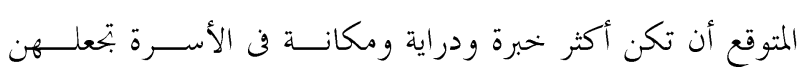

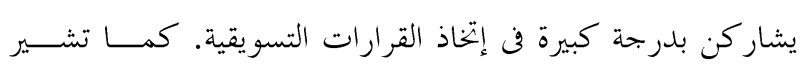

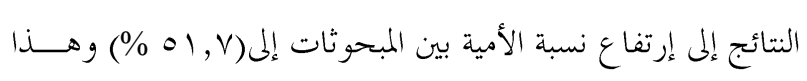

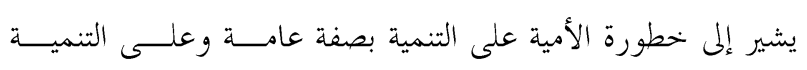

المناسب للظروف والإحتياجات والرغبات المختلفة للأسرة، والذى يحقق لها عائدا إقتصاديا مرتفعا و بالتالى يحقق مستوى معيشة أفضل أرعات. المشاركة في إتخاذ القرارات التسويقية: يقصد هها في هذه الدراسة

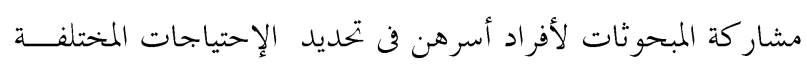

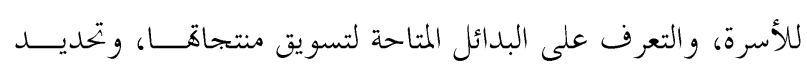

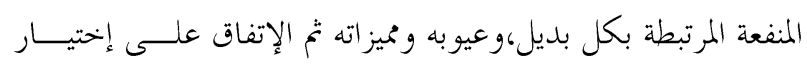
أفضلها تحقيقا لأهداف الأسرة. المعالجة الكمية لمتغيرات الدراسة:

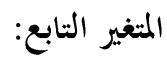
درجة مشاركة المبحوثــات فى إتخـــاذ القــــرارات التســـيقية:

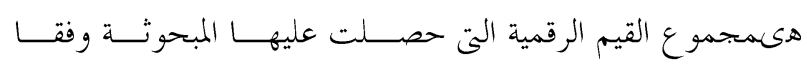

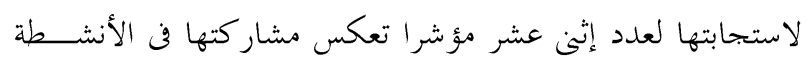

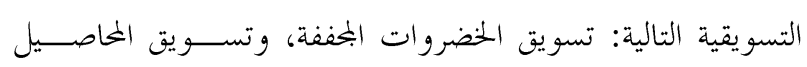

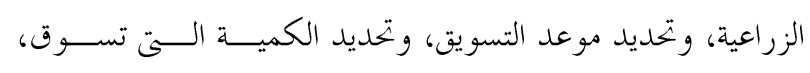

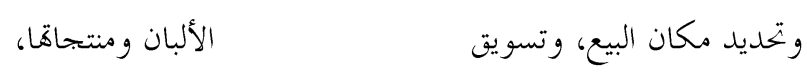

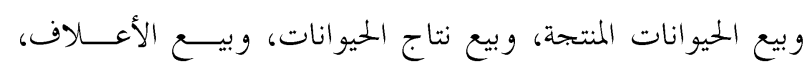
والتصرف في الدخل الناتج من التسويق، وتحديد أوجه الإســـثمار

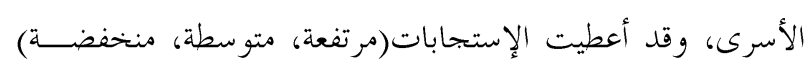

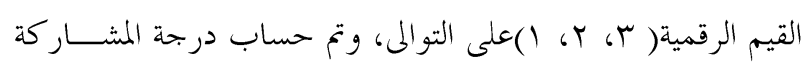
بجمع الدرجات التى حصلت عليها المبحوثة من تلك المؤشرات الإثنى

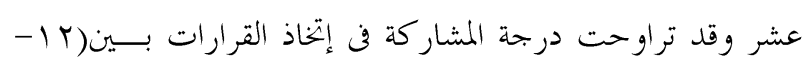

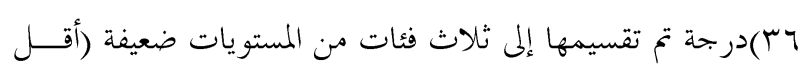

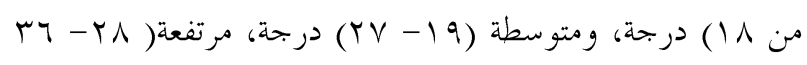
(برجة.

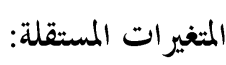

- تم إستخدام الأرقام الخام لقياس كل من: عمر المبحوثة، والسعة

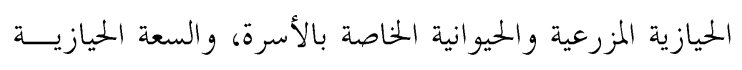

المزرعية والحيو انية الخاصة بالمبحوثة.

- الحالة التعليمية للمبحوثة: هى الإلمام بالقراءة والكتابة، والإنتقال

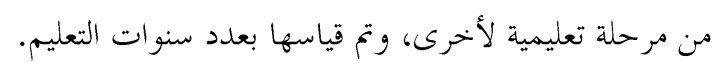




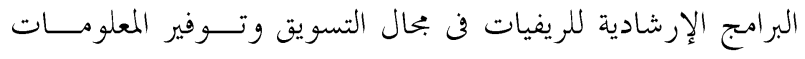

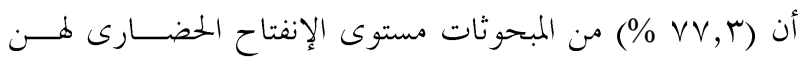
متوسط ومنخفض، وأن (r7\%) منهن مستوى الإنفتاح الثقافى لهن

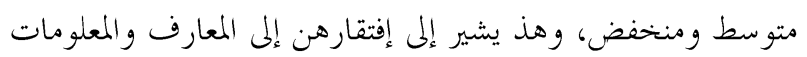

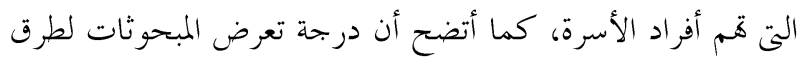

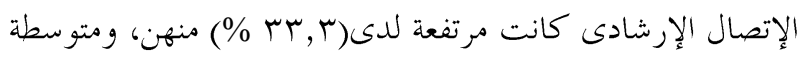

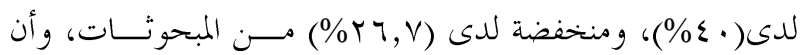

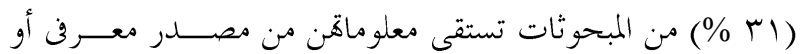

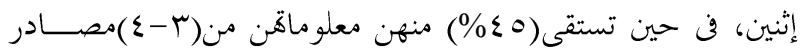

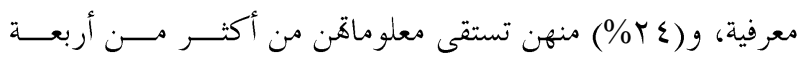

مصادر معرفية. - مصن اللازمة للإرتقاء بمستواهم المعرف في هذا المحال، كما تبين من النتائج

الريفية بصفة خاصة، في حين إنخفضت نسبة الأميــة بــين أزواج

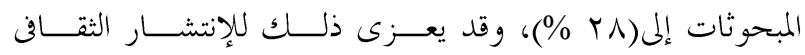

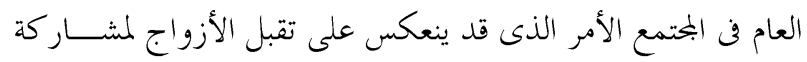
زوجاهم في إتخاذ القرارات التسويقية للمنتجات الزراعية والحيوانية. وقد تبين أن(• V \% من أسر المبحوثات تقل حيازهم المزرعية عن

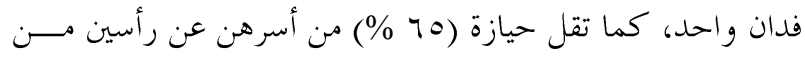

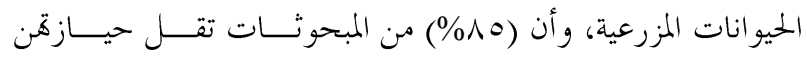

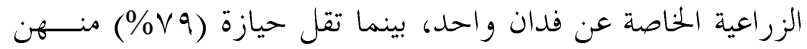

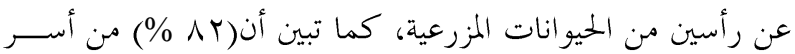
المبحوثات مستو اهم المعيشى متوسط ومنخفض، وهــــا يشــير إلى

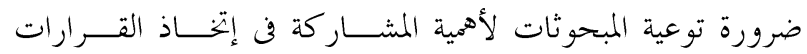
التسويقية الناجحة في الوقت المناسب لتحقيق دخل إضافى تســتطيع

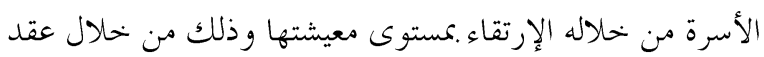

جدول ا ـ توزيع المبحوثات وفقا للخصائص المميزة لمن

\begin{tabular}{|c|c|c|c|c|c|}
\hline$\%$ & عدد & الخصائص & $\%$ & عدد & الخخصائص \\
\hline & & مستوى معيشة الأسرة ( درجة ) : & & & عمر المبحوثة ( سنة ) : \\
\hline rq,. & v. & - منخفض ( أقل من V) & $\Lambda, r$ & 10 & - \\
\hline$\varepsilon r$, & V V & - متوسط ( 1 - & ז & $11 \varepsilon$ & $\Sigma_{0}-Y_{0}-$ \\
\hline $1 \Lambda$, & זr & - مرتفع (W-IV & $r \wedge, r$ & 01 & 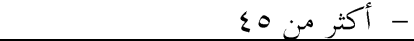 \\
\hline & & الإنفتاح الحضارى ( درجة ) : & & & الحالة التعليمية للمبحوثة \\
\hline $19,$. & $r \varepsilon$ & - منخفض ( أقل من س ) & $01, \mathrm{~V}$ & $q \pi$ & - \\
\hline $0 \wedge, r$ & 1.0 & - متوسط (r- - ( ) & $1 \varepsilon, \varepsilon$ & Y & تقرأ و تكتب : \\
\hline \multirow[t]{4}{*}{ rT,V } & $\leqslant 1$ & - مرتفع ( & r & $r \varepsilon$ & تعليم إبتدائى : \\
\hline & & & $\Lambda, r$ & 10 & تعليم إعدادى : \\
\hline & & & $1 \cdot, 7$ & 19 & تعليم ثانوى : \\
\hline & & & $1, \mathrm{~V}$ & r & - تعليم جامعى : \\
\hline & & الإنغتاح الثقافى ( درجة ) : & & & الحالة التعليمية للزوج : \\
\hline$r+1$ & $\varepsilon v$ & - منخفض ( أقل من r) & $r \wedge, r$ & 01 & \\
\hline$\{7,1$ & $\Lambda r$ & - متوسط (r - م) & lı, & זr & يقرأ وتكتب : \\
\hline \multirow[t]{5}{*}{$r \vee, \Lambda$} & $\circ$. & - مرتفع ( & 17,1 & rq & تعليم إبتدائى : \\
\hline & & & $r \backslash, \Lambda$ & rq & تعليم إعدادى : \\
\hline & & & 11,1 & $r$. & تعليم ثانوى : \\
\hline & & & $\varepsilon, \varepsilon$ & $\Lambda$ & - تعليم جامعي : \\
\hline & & التعرض للطرق الإرشادية ( درجة ) : & & & حيازة الآسرة : \\
\hline$r \uparrow, V$ & $\sum \Lambda$ & - منخفض ( أقل من V ) & $v \cdot, \cdot$ & 147 & - المزرعية (فدان ) : \\
\hline$\varepsilon \cdot, \cdot$ & VT & - متوسط ( & $r \varepsilon, \cdot$ & $\varepsilon r$ & $r-1$ \\
\hline \multirow[t]{2}{*}{ 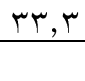 } & 7. & - مرتفع ('أكثر من عـا ) & $\uparrow$, & 11 & أكثر من r \\
\hline & & مصادر المعلومات ( مصدر ) : & & & حيازة الأسرة : \\
\hline r, & 04 & $(r-1)-$ & 70, & $11 \mathrm{~V}$ & - الحيوانية (رأس ) : \\
\hline$\varepsilon 0,$. & $\wedge 1$ & $(\varepsilon-r)-$ & $r \wedge, r$ & 01 & $\varepsilon-r$ \\
\hline \multirow[t]{5}{*}{$r \varepsilon, \cdot$} & $\varepsilon r$ & - & $\mathrm{T}, \mathrm{V}$ & Ir & أكثر من ع \\
\hline & & & & & الحيازة الحخاصة بالمبحوثة : \\
\hline & & & ^०, $\cdot$ & 104 & - المزرعية ( فدان ) : \\
\hline & & & 10, & rV & ${ }^{r}$ \\
\hline & & & 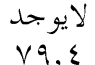 & لايوجد & أكثر من ب \\
\hline
\end{tabular}




\begin{tabular}{|c|c|c|}
\hline 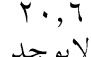 & vV & $\varepsilon-Y^{2}$ \\
\hline
\end{tabular}

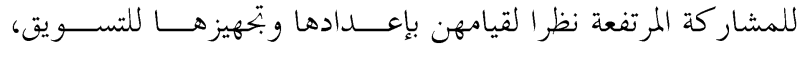

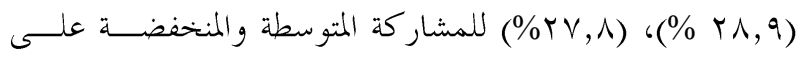

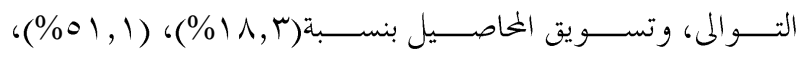

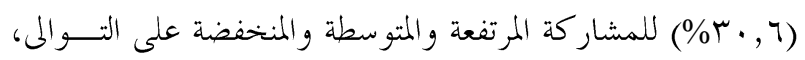

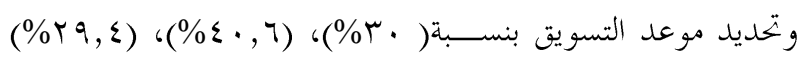

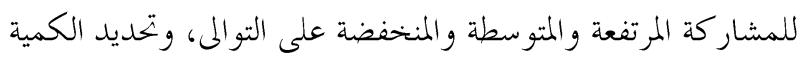

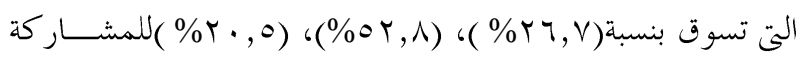

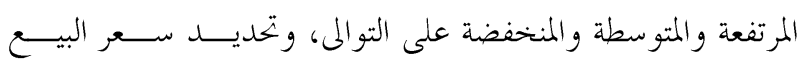

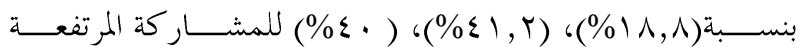

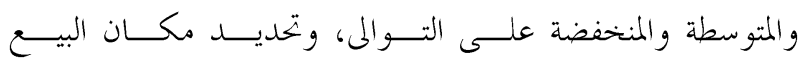

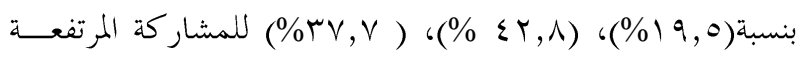
و المتو سطة والمنخفضةعلى التوالى. ب- درجة مشاركة المبحوثات فى إتخاذ القـــرارات التســــيقية

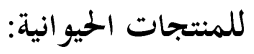
أوضحت النتائج الواردة بجدولى ـ أن درجة مشار كة أكثر من

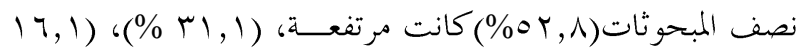

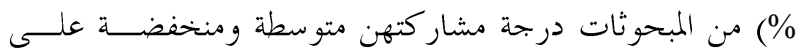

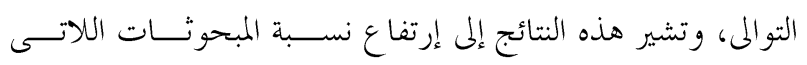

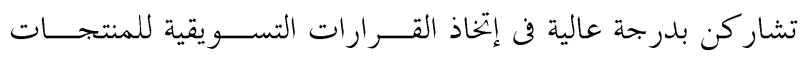
الحيوانية، وهذا يعكس أهمية دور المرأة ومسئوليتها في تربية ورعاية الحيو انات المزرعية وتسويقها وإعداد وتسويق منتجاها.

ثانيا: درجة مشار كة المبحوثات في إتخاذ القــــارات التســــيقية للمنتجات النباتية والحيو انية: أ- درجة مشاركة المبحوثات فى إتخـــاذ القــــارات التســــيقية

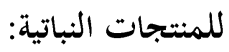

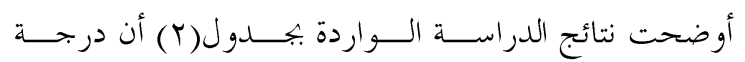

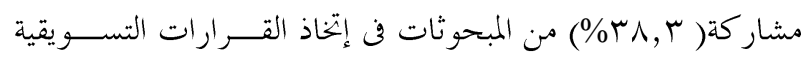
للمنتجات النباتية كانت منخفضة، (اءع\%) منهن درجة مشار كتهن

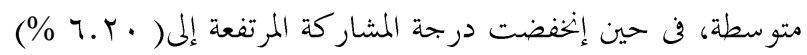

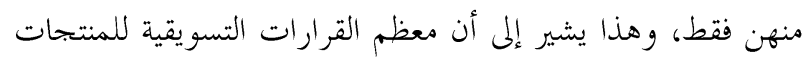

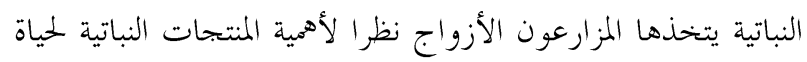

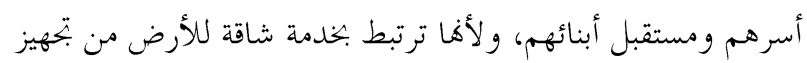

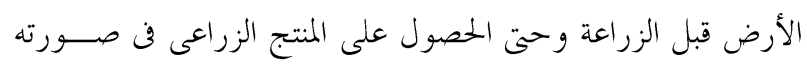

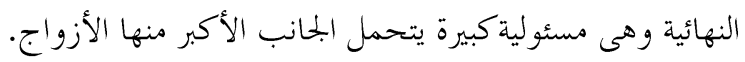

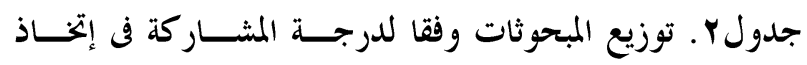
القرارات التسويقية للمنتجات النباتية

\begin{tabular}{|c|c|c|}
\hline$\%$ & عدد & درجة المشاركة (درجة ) \\
\hline$r \cdot, \uparrow$ & rV & - مرتفعة (乏) - ( $1 \wedge)$. \\
\hline$\varepsilon 1,1$ & $v \varepsilon$ & - متوسطة (q - 1 ( )). \\
\hline$r \wedge, r$ & 79 & - منخفضة (أقل من 9). \\
\hline$\cdots$ & 11. & إجمالي \\
\hline
\end{tabular}

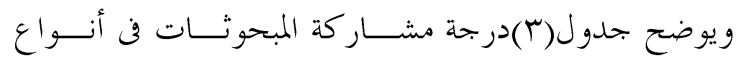

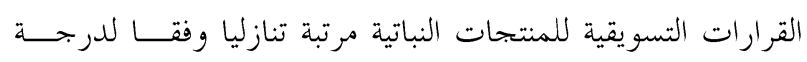

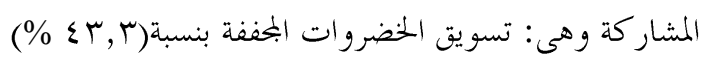
جدول ب. توزيع المبحوثات وفقا لدرجة المشاركة فى نوعية القرارات التسويقية للمنتجات النباتية

\begin{tabular}{|c|c|c|c|c|c|c|}
\hline \multicolumn{6}{|c|}{ درجة المشاركة } & \multirow{3}{*}{ أنواع القرارات } \\
\hline \multicolumn{2}{|c|}{ منخفضة } & \multicolumn{2}{|c|}{ متو سطة } & \multicolumn{2}{|c|}{ مرتفعة } & \\
\hline$\%$ & تكر ار & $\%$ & تكك ار & $\%$ & تكـ ار & \\
\hline$r V, \Lambda$ & 0 . & $r \wedge, q$ & OY & $\varepsilon r, \mu$ & $\vee \wedge$ & - تسويق الخضرووات المفففة. \\
\hline$r \cdot, \uparrow$ & 00 & 01,1 & 94 & $1 \wedge, \Gamma$ & זr & - تسويق المحاصيل. \\
\hline rq, ६ & or & $\varepsilon \cdot\rceil$, & VT & $r \cdot, \cdot$ & o & - تحديد موعد التسويق. \\
\hline$r \cdot, 0$ & rV & $O r, \Lambda$ & 90 & $r \uparrow, V$ & $\sum \Lambda$ & - تحديد الكمية التي تسوق. \\
\hline$\varepsilon \cdot, \cdot$ & VY & $\varepsilon 1, r$ & $V \varepsilon$ & $1 \wedge, 1$ & $r \varepsilon$ & - تحديد سعر البيع. \\
\hline$r v, \mathrm{~V}$ & 71 & $\sum r, \Lambda$ & VV & 19,0 & ro & - تحديد مكان البيع. \\
\hline
\end{tabular}

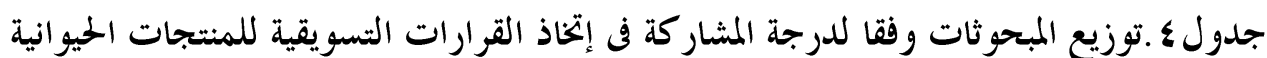

\begin{tabular}{|c|c|c|}
\hline$\%$ & عدد & درجة المشاركة (درجة ) \\
\hline$O Y, \Lambda$ & 90 & - مرتفعة (1)-1^-1). \\
\hline
\end{tabular}




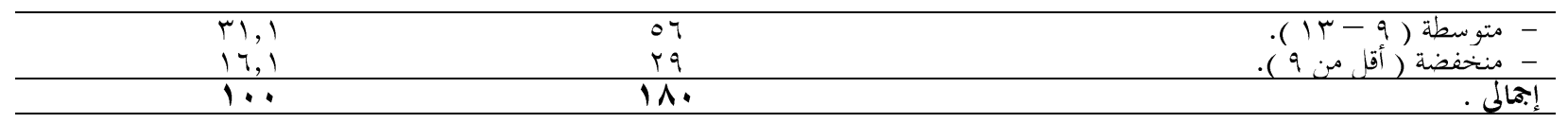

وتوضح البيانات الواردة بجدول(0) درجة مشاركة المبحوثات المعلومات:

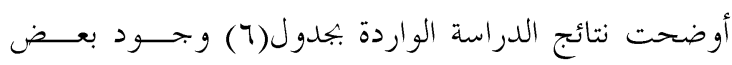

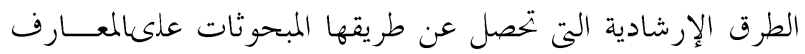

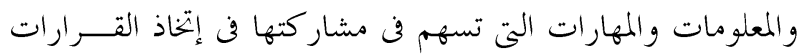

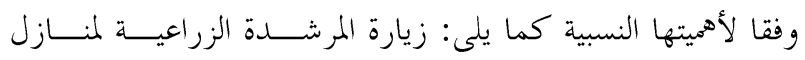

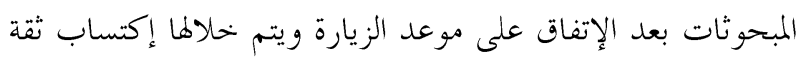

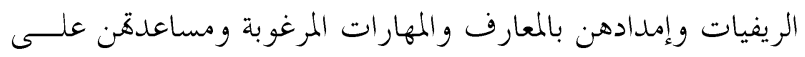

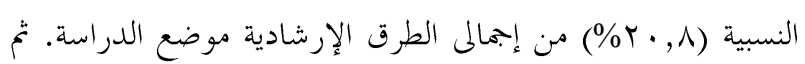

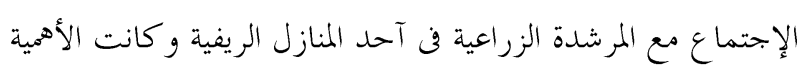

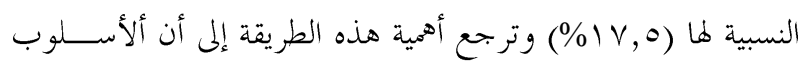

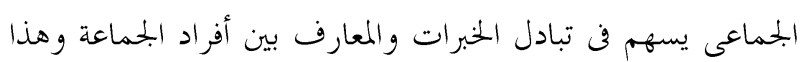
يسهم في إبحاح برامج وأنشطة الإرشاد الزراعى الموجهة لبهات للريفيات.

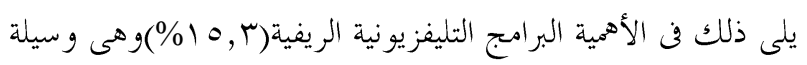

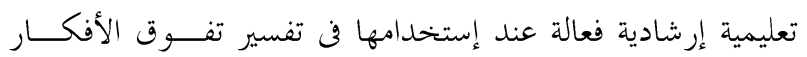

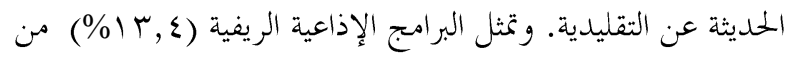

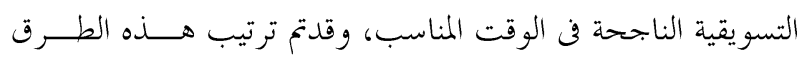

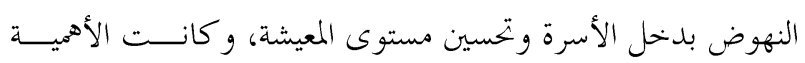

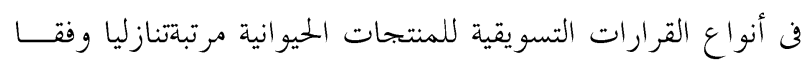

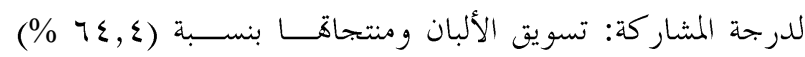

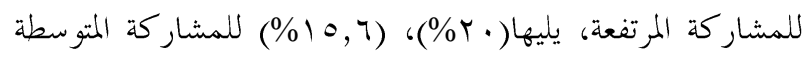

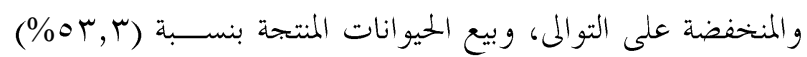

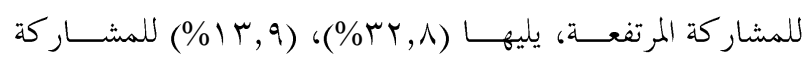

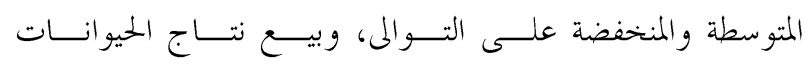

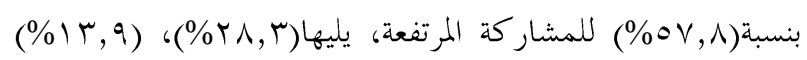

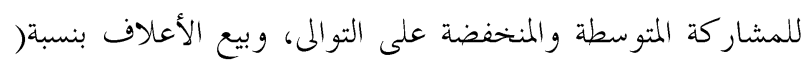

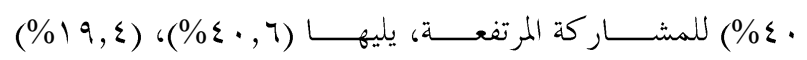

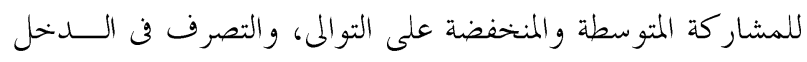

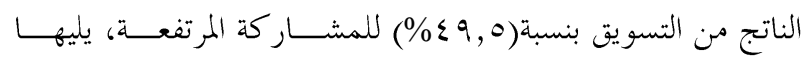

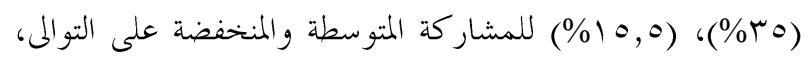

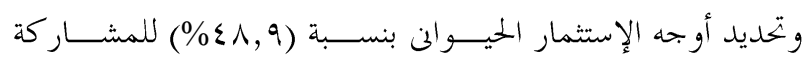

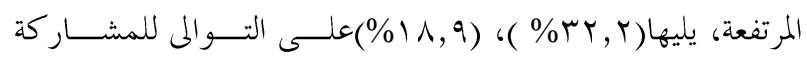
المتو سطة والمنخفضة.

ثالثا: الطرق الإرشادية التى تتعرض لها المبحوثات وأهم مصادر

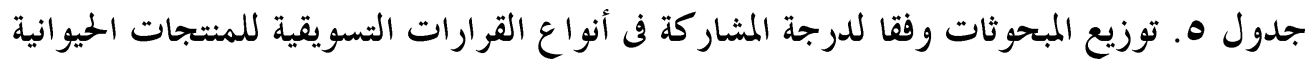

\begin{tabular}{|c|c|c|c|c|c|c|}
\hline \multicolumn{6}{|c|}{ درجة المشاركة } & \multirow{3}{*}{ 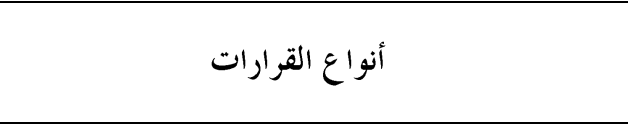 } \\
\hline \multicolumn{2}{|c|}{ منخفضة } & \multicolumn{2}{|c|}{ متو سطة } & \multicolumn{2}{|c|}{ مر تفعة } & \\
\hline$\%$ & تكرار & $\%$ & تكرار & $\%$ & تكرار & \\
\hline 10,7 & rی & $r \cdot, \cdot$ & 4 & $T \varepsilon, \varepsilon$ & 117 & - - تسويق الألبان ومنتجاهّا. \\
\hline 14,9 & ro & 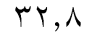 & 09 & Or, r & 97 & - - بيع الحيوانات المنتجه. \\
\hline 14,9 & ro & $r \wedge, r$ & 01 & $\circ \vee, \Lambda$ & $1 \cdot \varepsilon$ & - - بيع نتاج الحيوانات. \\
\hline $19, \varepsilon$ & ro & $\varepsilon \cdot\rceil$, & $\mathrm{VT}$ & $\varepsilon \cdot, \cdot$ & Vr & - بيع الأعلاف. \\
\hline 10,0 & ru & $\mu_{0},$. & זד & $\varepsilon 9,0$ & 19 & - التصرف في الدخل الناتج من التسويق. \\
\hline \multirow[t]{10}{*}{11,9} & $r \varepsilon$ & rY, & $0 \wedge$ & $\varepsilon \wedge, q$ & $\Lambda \Lambda$ & - تحديد أوجه الإستثمار الحيوان . \\
\hline & & \multicolumn{5}{|c|}{ جدول \. يبين الطرق الإرشادية التى تتعرض لها المبحوثات وفقا للنسب المئوية للتكرارات } \\
\hline & \% لتكرارات & \multicolumn{2}{|c|}{ تكرار } & \multicolumn{3}{|c|}{ الطرق الإرشادية } \\
\hline & $r \cdot, \Lambda$ & \multicolumn{2}{|r|}{ rr } & \\
\hline & IV,o & \multicolumn{2}{|r|}{114} & & & \\
\hline & $10, r$ & \multicolumn{2}{|r|}{$9 \wedge$} & & & \\
\hline & $1 \%, \varepsilon$ & \multicolumn{2}{|r|}{14} & \\
\hline & Ir, & \multicolumn{2}{|r|}{ VV } & & & \\
\hline & $1 \cdot, \wedge$ & \multicolumn{2}{|r|}{79} & \\
\hline & $\cdot, r$ & & $T \varepsilon$ & & & \\
\hline
\end{tabular}


المباشر عن الطرق ذات التأثير المباشر إلى رغبة المبحوثات في إختيار

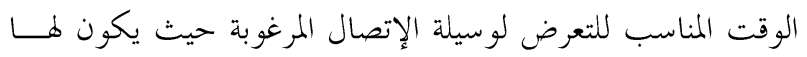

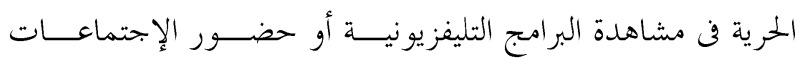
الإرشادية، أو زيارة المشاريع التنموية.

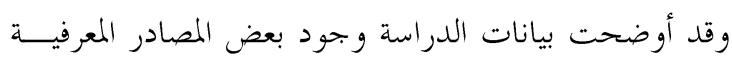

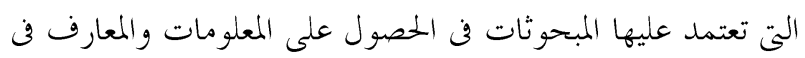

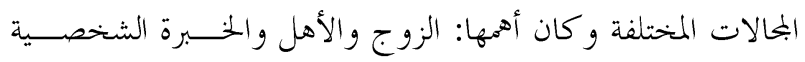
و المرشدة الزراعية والبرامج التليفزيونية. (جدوله). جدول ^ـ. توزيع المبحوثات وفقا لمصادر المعلومات المفضلة

\begin{tabular}{|c|c|c|}
\hline \% للتكرارات & تكرار & مصادر المعلومات \\
\hline$r v, 1$ & 17. & - الزو ج. \\
\hline$r, r$ & 141 & - الأهل. \\
\hline$\curlywedge \wedge, \wedge$ & 111 & - الخبرة الشخصية. \\
\hline \, ₹ & 1.9 & - المرشدة الزراعية. \\
\hline $1 \%, 0$ & $\Lambda$. & - البرامجج التليفزيونية. \\
\hline $1 \ldots$ & 091 & مجمو ع التكرارات \\
\hline
\end{tabular}

رابعا: الطرق الإرشادية كأحد المتغيرات المرتبطة والمؤثرة علــى درجة مشاركة المبحوثات فى إتخاذ القرارات التسويقية للمنتجات النباتية والحيو انية:

أوضحت نتائج التحليل الإرتباطى البسيط لبيرسون بين بعض

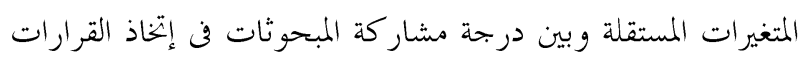

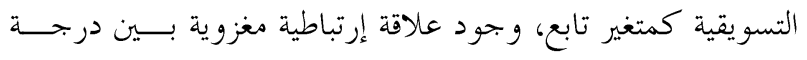

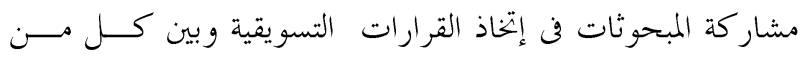

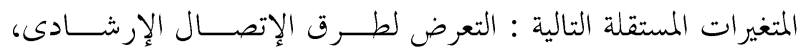

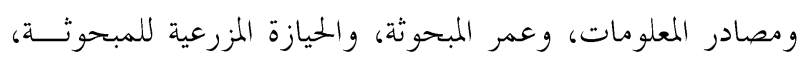
والحيازة الحيو انية للمبحوثة.

وقد تبين أن معامل الإرتباط المتعدد بين المتغيرات المستقلة وبين

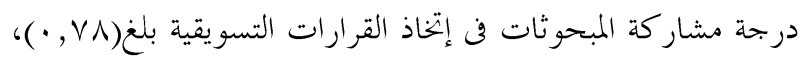

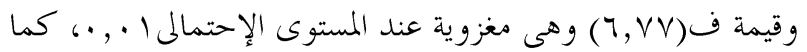

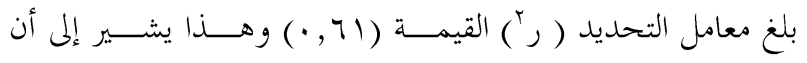

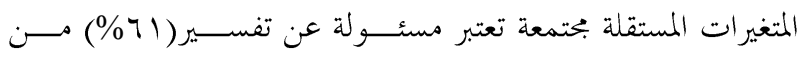

الأهمية النسبية وهى وسيلة هامة لإرشاد الجماهير حيث تستمع إليها

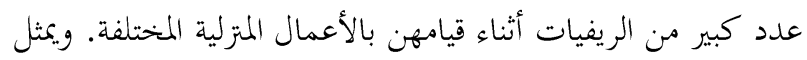

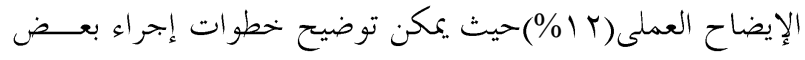

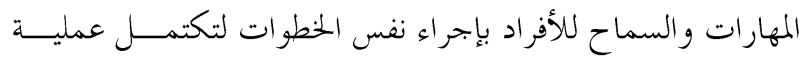

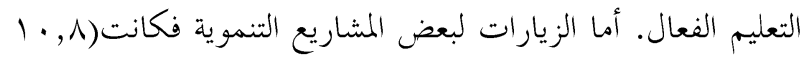

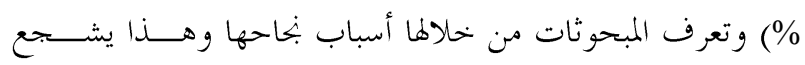

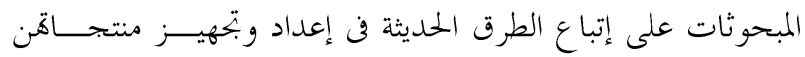

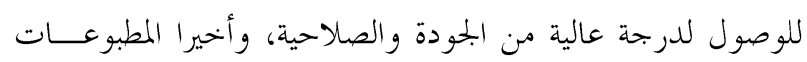

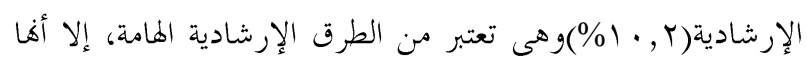

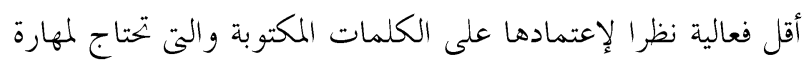
القراءة وهى لاتتوفر عندما ترتفع نسبة الأمية بين المبحوثات.

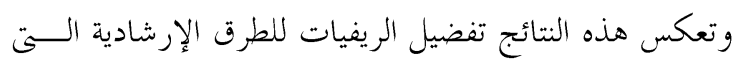

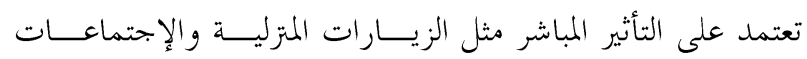

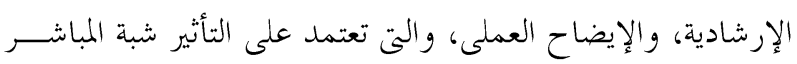

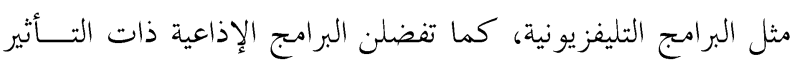
غير المباشر حيث يمكنها سماع ما ترغبة أثناء قيامها بالأعمال المتزلية

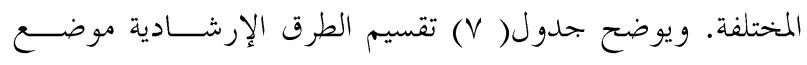

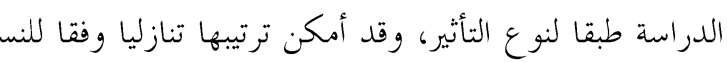

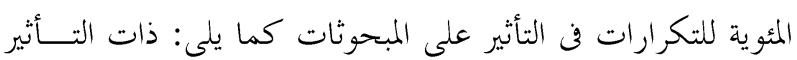

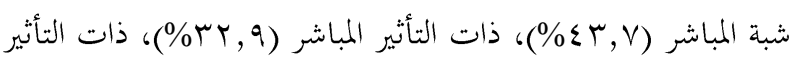

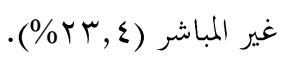

جدول V. توزيع المبحوثات وفقا لنوع تأثير الطرق الإرشــادية

المفضلة

\begin{tabular}{|c|c|c|}
\hline \% \% للتكرارات & تكرار & الطرق الإرشادية وفقا لنو ع التأثير \\
\hline$\varepsilon r, V$ & rVq & - ذات التأثير شبة المباشر. \\
\hline$r r, q$ & r). & ذات التأثير المباشر. \\
\hline$r \Psi, \varepsilon$ & 10. & - ذذات التأثير غير المباشر. \\
\hline $1 \ldots$ & 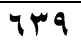 & مجمو ع التك ارات \\
\hline
\end{tabular}

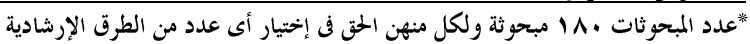

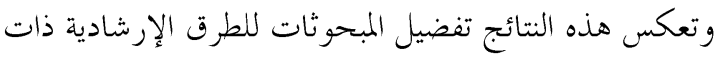

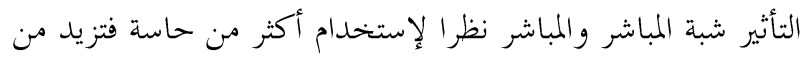

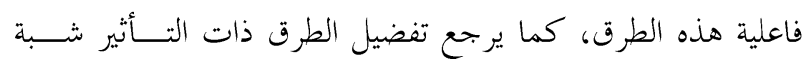


أسرقا أعلى، ويكون لها الحق في إتخاذ القرارات التسويقية بإعتبارها من موارد الدخل الهامة والأساسية للأسرة. كما إتضح أن قيمة معامل الإنحدار الجزئى للمــتغير الحيــازة

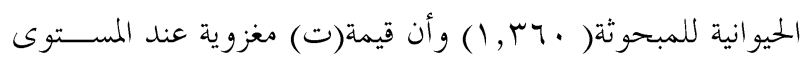

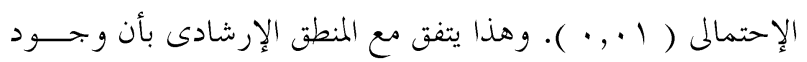

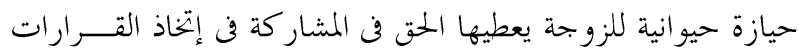
التسويقية الناجحة نظر الإعتبارها من مصادر دخل الأسرة. كما تبين من النتائج أن قيمة معامل الإنحار الجزئى للمــتغير

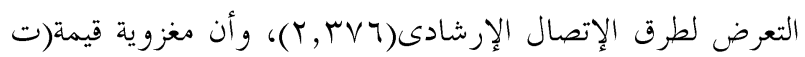

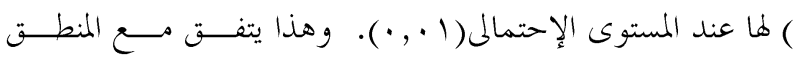

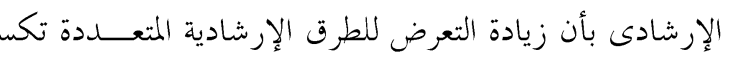

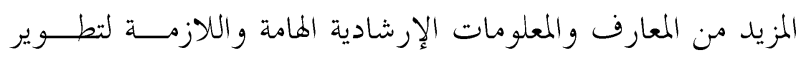

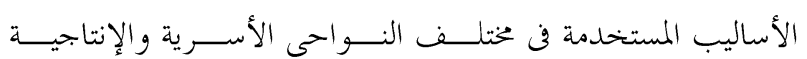

$$
\text { و التسويقية للإرتقاء .مستوى معيشة الأسرة. }
$$

كما إتضح أن قيمة معامل الإنحدار الجزئى للمـتغير مصــادر

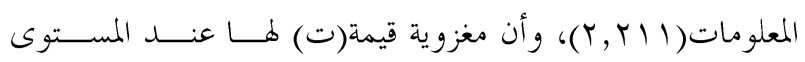

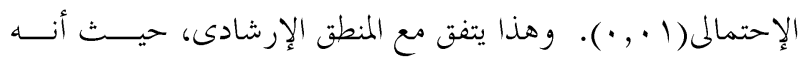

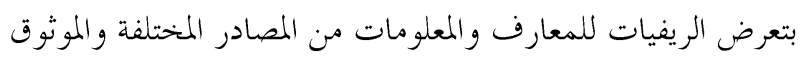

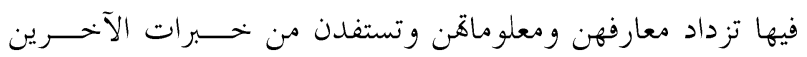

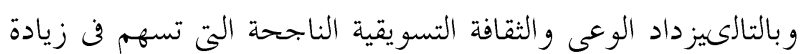
دخل الأسرة وتحسين مستوى معيشتها.
التباين في مدى الدور الذى تلعبة خصائص الريفيــات فن درجـــة

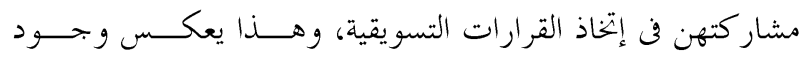

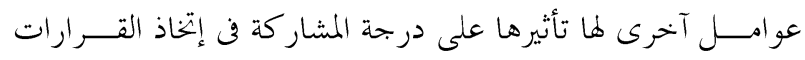

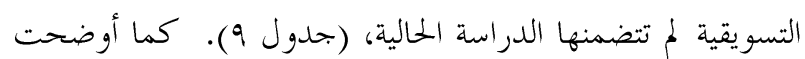
النتائج عدم مغزوية معاملات الإنحدار الجزئي للمتغيرات المســتقلة

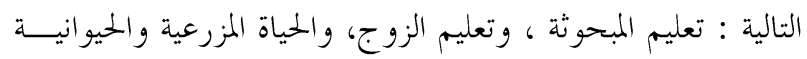
للأسرة، ومستوي المعيشة، والإنفتاح الخضاري، والإنفتاح الثقاين،

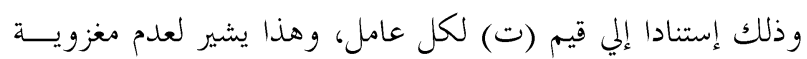

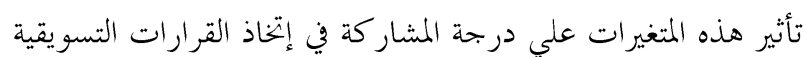

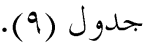

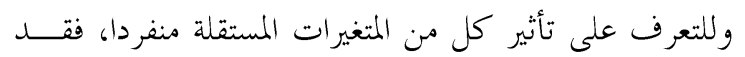

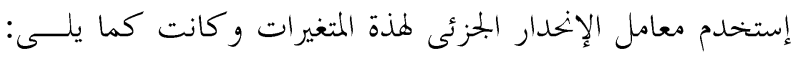

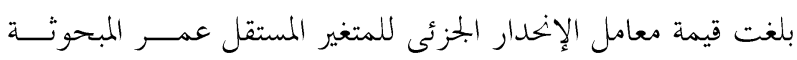

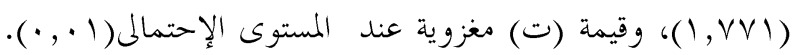

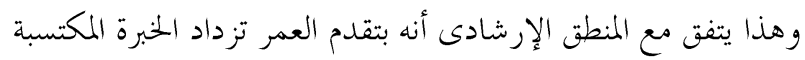

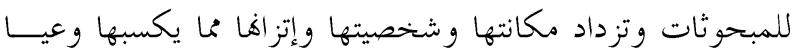

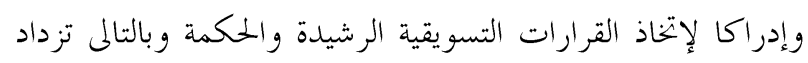

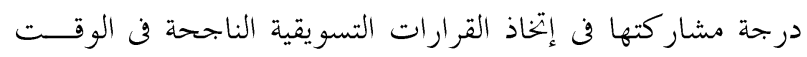
المناسب.

كما تبين أن قيمة معامل الإنحدار الجزئى للمــتغير المســتقل

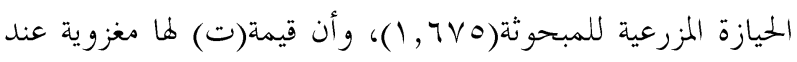

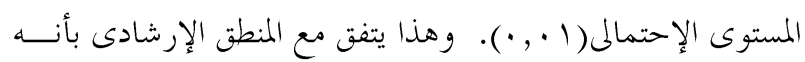

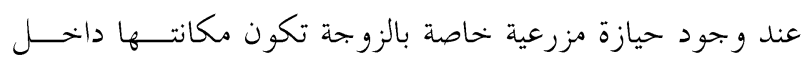

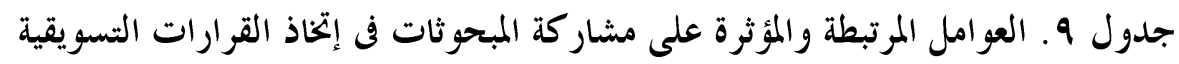

\begin{tabular}{|c|c|c|c|c|c|}
\hline الترتيب التاثيرى & معامل الإنحدار الجزئى & قيمة (ت) & معامل الإنحدار & معامل الإرتباط البسيط & المتغير ات المستقلة \\
\hline \multirow[t]{5}{*}{ r } & $\cdot, \mu \circ V$ & *** 1,77 & $1, \vee \vee 1$ & $* * *, 001$ & عمر المبحوثة. \\
\hline & - & $1, \cdot 7$ &., $.0 \mathrm{~V}-$ &., $10 \mathrm{~V}$ & تعليم المبحوثة. \\
\hline & $\cdot|r|-$ & س &., $107-$ & r, & تعليم الزو ج. \\
\hline & $\cdot, \cdot \vee 1$ & $\cdot, 97$ & $\cdot, \cdot \leq q$ & $\cdot, 1 \leq \varepsilon$ & الحيازة المزرعية للأسرة. \\
\hline & $\cdot, \cdots \wedge-$ & $\cdot, \vee V$ & $\cdot, Y \backslash Y$ & $\cdot, 109$ & الحيازة الحيوانية للأسرة. \\
\hline$\varepsilon$ & $\cdot$, Y०Y & *** $r, 10$ & $1,7 \vee 0$ & * שr, & الحيازة المزرعية للمبحوثة. \\
\hline \multirow[t]{4}{*}{ ○ } & סטr, & *** 1,07 & 1, & $* ., 011$ & الحيازة الحيو انية للمبحوثة. \\
\hline & $\cdot, \cdot \vee\urcorner$ & $\cdot, \cdot \wedge$ & $\cdot, .17$ & $\cdot, 11 \mathrm{~V}$ & مستوى المعيشة. \\
\hline & $\cdot,+9-$ & $1, \cdot \varepsilon$ & $\cdot, \cdot 1 \mathrm{r}$ & $\cdot, Y \backslash 1$ & الإنغتاح الحضارى. \\
\hline & $\cdot, 1 \cdot v$ & $\cdot, 97$ & - & $\cdot, 1 Y_{7}$ & الإنفتا ح الثقافى. \\
\hline 1 &., $0 \vee T$ & *** $\{, 9 \uparrow$ & r, rVY & ע & التع ضرض للطرق الإرشادية. \\
\hline
\end{tabular}




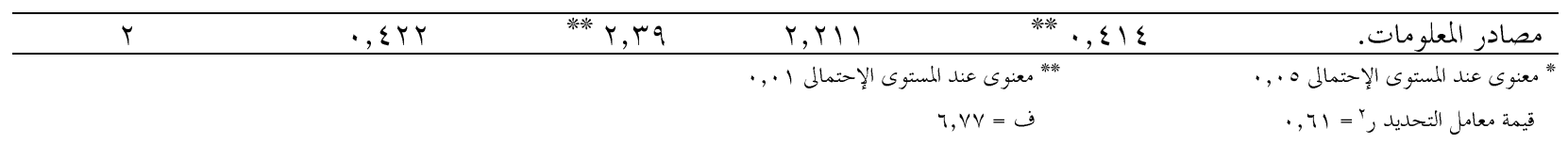

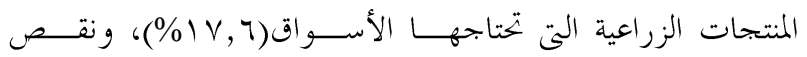

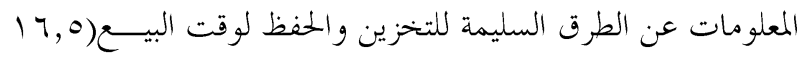
\%)، والحاجة للتدريب على الطرق السليمة لتصنيع الفائض الزراعى

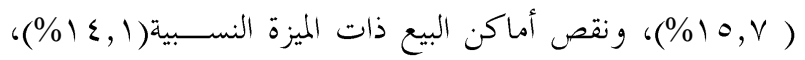

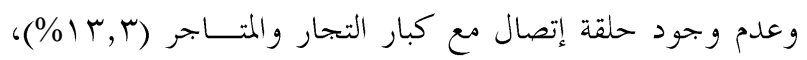

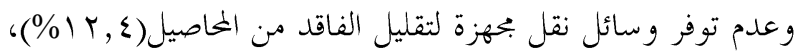
نقص المعرفة مكصادر الحصول على قــروض ميســرة (ع, •ا1\%). جدول(·) (1) (1) (2)

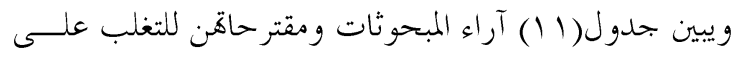
المشاكل التي تعوق مشاركتهن في إتخاذ القرارات التسويقية السليمة

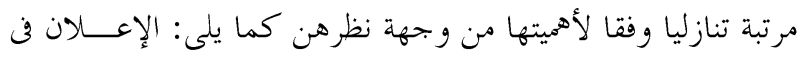

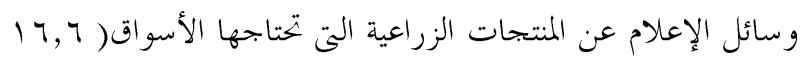

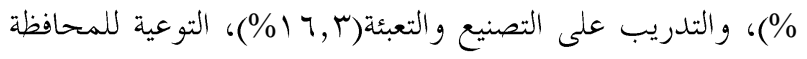
على المنتجات المعدة للتخزين أطول فترة صالحة للإستخدام ( 10,0

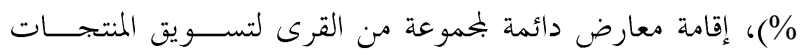

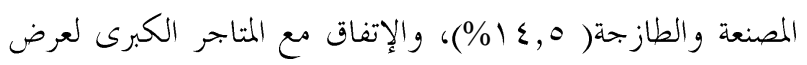

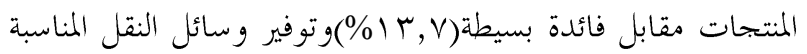

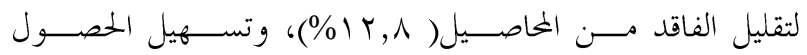
على قروض بسيطة وميسرة (1, · (1\%).
ومن معاملات الإنحدار الجزئي القياسى يمكن تحديد الأهميــة

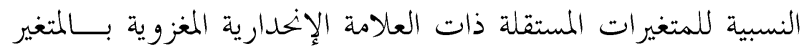
التابع درجة المشاركة في إتخاذ القرارات التسويقية من خلال ترتيبها

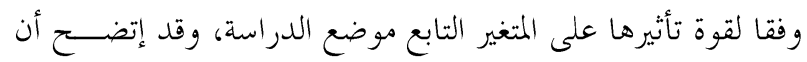

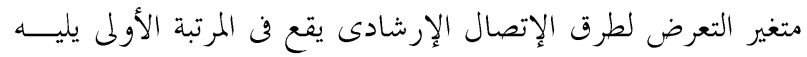

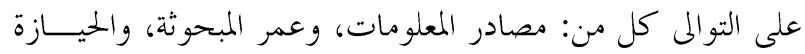

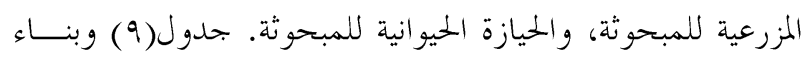
على نتائج التحليل الإنحارى فإنه يمكن رفض الفرض الإحصائى في

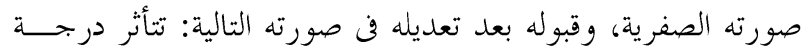

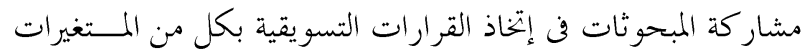

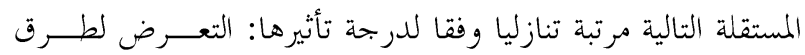
الإتصال الإرشادى، مصادر المعلومات، عمر المبحوثــة، الحيــازة المزرعية للمبحوثة، الحيازة الحيو انية للمبحوثة.

خامسا: أهم المشاكل التى تعوق المشاركة في إتخـــاذ القــــرارات

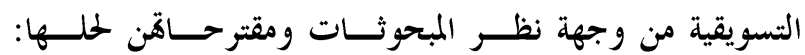
أهم المثاكل التى تعوق المشاركة في إتخاذ القرارات التسويقية:

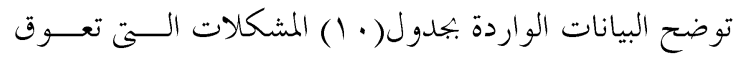

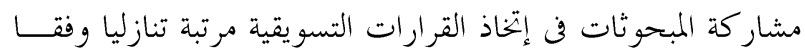

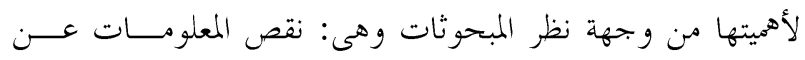

جدول • ا ـ يبين أهم المشاكل التى تعوق مشار كة المبحوثات فى إتخاذ القرارات التسويقية

\begin{tabular}{|c|c|c|}
\hline$\%$ & تكرار & المشاكل \\
\hline IV,T & ITV & نقص المعلومات عن المنتجات الزراعية التى تحتاجها الأسواق. \\
\hline 17,0 & 119 & نقص المعلومات عن الطرق السليمة للتخزين و الحفظ لوقت البيع. \\
\hline $10, \mathrm{~V}$ & $11 \mathrm{r}$ & الحاجة للتدريب على الطرق السليمة لتصنيع الفائض الزراعى. \\
\hline $1 \leqslant, 1$ & 1.1 & نقص أماكن البيع ذات الميزة النسبية. \\
\hline $1 \mu, r$ & 97 & عدم وجود حلقة إتصال مع كبار التجار والمتاجر. \\
\hline Ir, & 19 & عدم توفر وسائل نقل بحهزة لتقليل الفاقد من الخحاصيل. \\
\hline $1 \cdot, \varepsilon$ & vo & نقص المعرفة عن مصادر الخصول على قروض ميسرة. \\
\hline
\end{tabular}

جدول ال ا ـ يبين مقتر حات المبحوثات فى حل المشاكل التى تعوق مشار كتهن فى إتخاذ القرارات التسويقية

\begin{tabular}{|c|c|c|}
\hline$\%$ & تكرار & 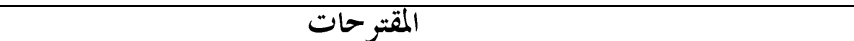 \\
\hline 17,7 & $1 \pi V$ & الإعلان فن و سائل الأعلام عن المنتجات الزراعية التى تحتاجها الأسواق. \\
\hline 17, r & 1To & \\
\hline 10,0 & $1 \mathrm{~K}$ & التوعية للمحافظة على المنتجات المعدة للتخز ين أطول فترة صالحة للإستخدام. \\
\hline $1 \varepsilon, 0$ & $1 \%$. & إقامة المعارض الدائمة بخموعة قيى لتسويق منتجاها الطازجة و المصنعة. \\
\hline
\end{tabular}




\begin{tabular}{|c|c|c|}
\hline IT,V & $11 \pi$ & الإتفاق مع المتاجر الكبرى لعرض المنتجات مقابل فائدة بسيطة. \\
\hline $\mid r, \Lambda$ & $1 \cdot 7$ & توفير و سائل نقل مناسبة لتقليل الفاقد عند نقل الغحاصيل. \\
\hline $1 \cdot, 7$ & $\wedge \wedge$ & تسهيل الحصول على قروض بسيطة وميسرة. \\
\hline
\end{tabular}

الجنجيهى، هدى محمد، مستقبل العمل الإرشادى الزراعى مــع المـــــأة

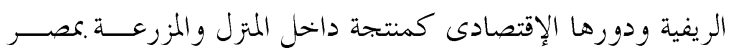

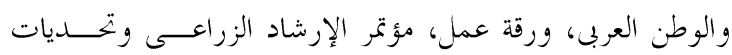

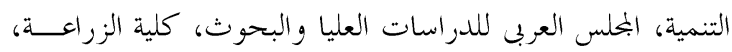

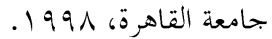
الجهاز المركزى للتعبئة العامة والإحصاء، نتائج التعداد العام للســكان

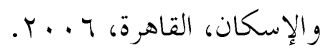

الحُولى، حسين زكى، الإرشاد الزراعى ودورة فـ تطـــوير الريــف، دار

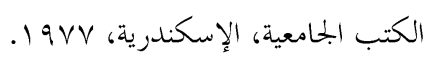

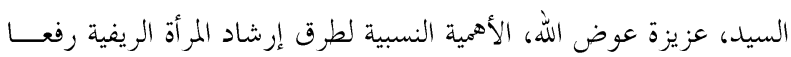

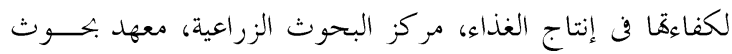

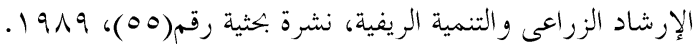

الطنوب،، محمد عمر، مرجع الإرشاد الزراعى، دار النهضة العربية للطباعة

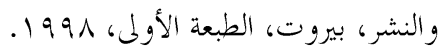
العادلى، أحمد السيد، أساسيات علم الإرشاد الزراعى، دار المطبوعــات

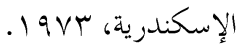

الشيخ، إيناس إبراهيم، فرص العمل و التوظيف في ظل المشروعات القومية

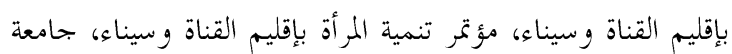

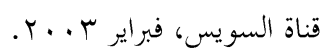

أمين، صفاء أحمد، دراسة حول دور الزوجة الريفية في عملية إتخاذ القرار

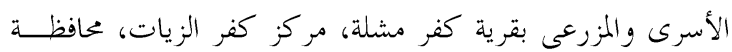
الغربية، المؤتمر الثان للإقتصاد و التنمية فن مصر و البلاد العربية، كلية

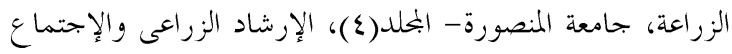

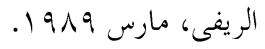

حسن، بنوى عبد الرحمن، طلبة، ليلى أنور، حسيب، هيام محمد، دراسة

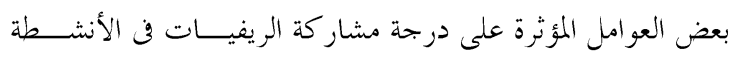

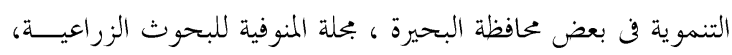

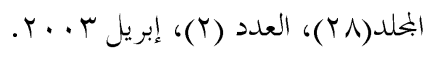

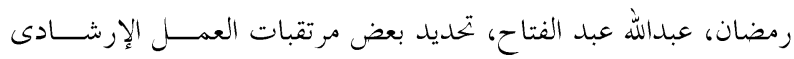

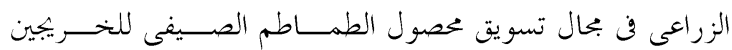

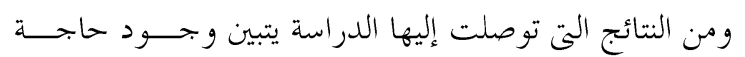

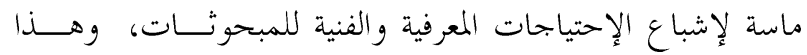
يضيف مزيدا من العبء على جهاز الإرشاد الزراعى لتوفير تلــك لـك

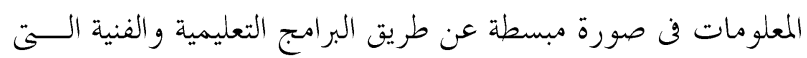
تدفع الريفيات إلى زيادة الكفاءة الإنتاجية، وهذا يتم من خلال توفير

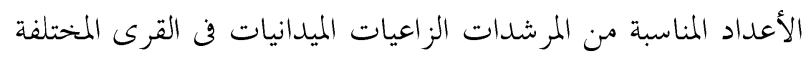

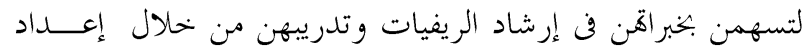

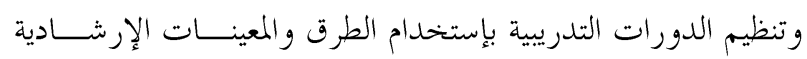

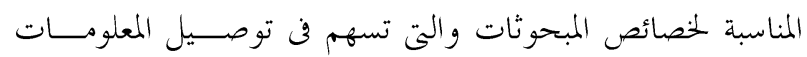

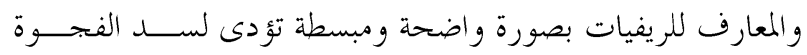

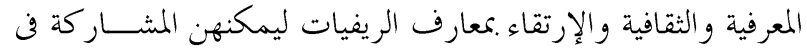

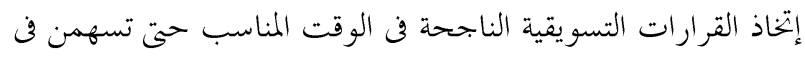
زيارة دخل الأسرة الذى ينعكس على الإرتقاء بمستوى معيشتها. و بناءا على ما تقدم توصى الدراسة بإهتمام الجهاز الإرشادى

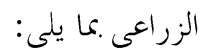
- تخصيص فقرة إعلانية في وسائل الإعلام الجماهيرى للتوعية عـن

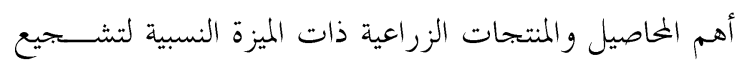

$$
\text { الزراع على زراعتها في المواسم المختلفة. }
$$

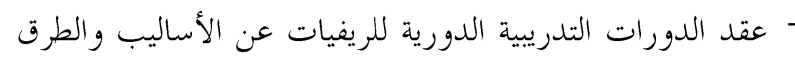

$$
\text { السليمة للتصنيع و التعبئة والحفظ. }
$$

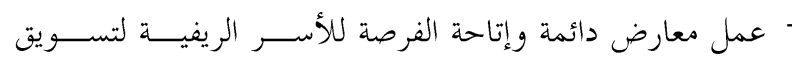
منتجاها مقابل فائدة بسيطة ومناسبة. - تسهيل حصول الأسر الريفية على قروض بسيطة للمساعدة على

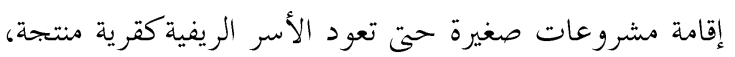

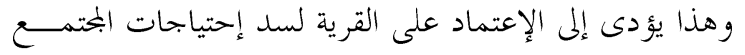
من المنتجات الريفية و الغذائية كسابق عهدها.

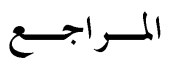




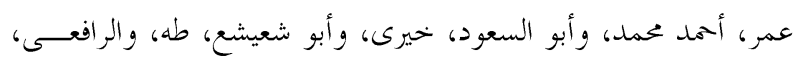

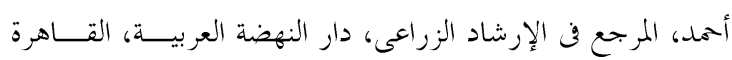

$.19 \mathrm{VT}$

فهمى، عفاف ميخائيل، الأهمية النسبية لمصادر معلومات قائدات الرأى

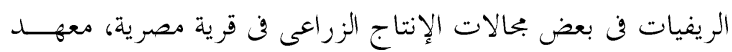

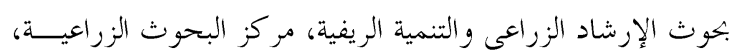

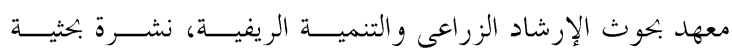

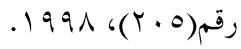

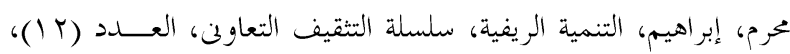

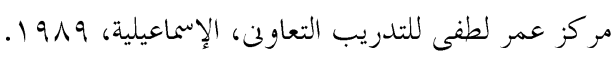

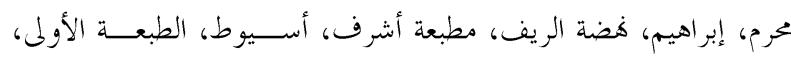
.$r \cdot \varepsilon$ محمد، زينب على، ترشيد مشار كة الريفيات في إتخاذ القرارات التسويقية

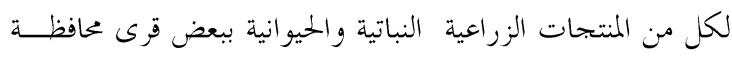

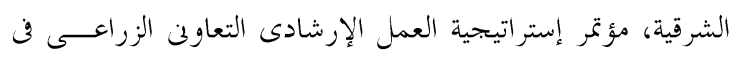

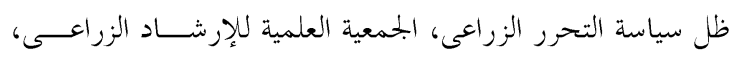
.1997

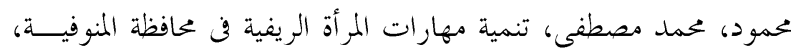

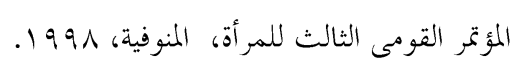

نويصر، إبراهيم محمد، فودة، حسنه محمد، المتطلبات الإرشادية لمشاركة

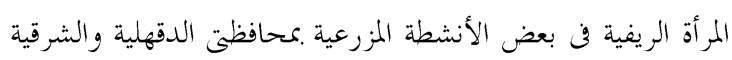

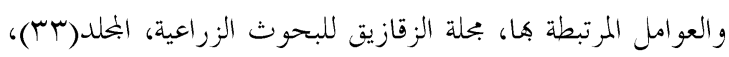

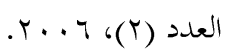

El-Monoufi, K.(1981)"Popular Participation and Development in village of Egypt". The national Review of Social Science, vol. 18.

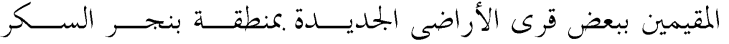

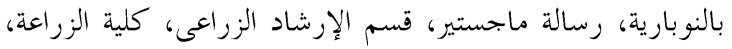

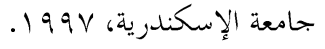

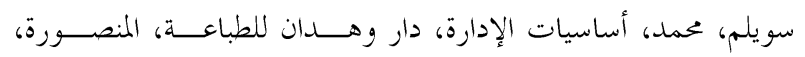
.1991

سويلم، محمد نسيم على، الإرشاد الزراعى، مصر للخدمات العلميــة، $.19916199 \mathrm{~V}$

شبلى، محمد يوسف، الصاوى، الصاوى محمد، حلمى، أحمد فؤاد، دراسة

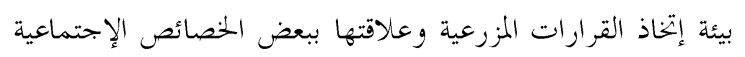

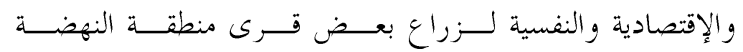

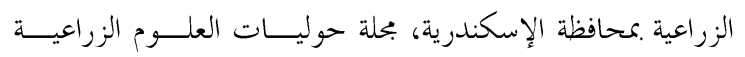

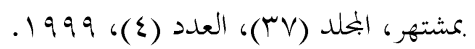
صالح، صبرى مصطفى، طرق ومعينات الإتصال الإرشادى الزراعسى،

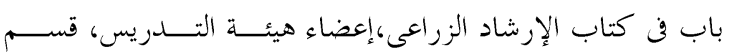
الإرشاد الزراعى، كلية الزراعة، جامعة الإسكندرية، ـ199. 19.

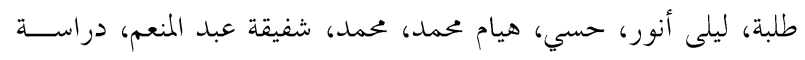

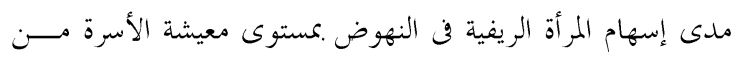

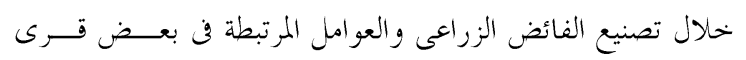

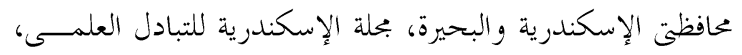

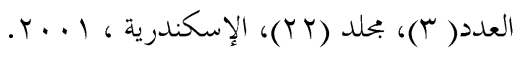
طلبة، ليلى أنور، حسيب، هيام محمد، دراسة أثر بعض الطرق الإرشادية

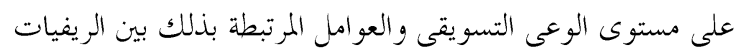

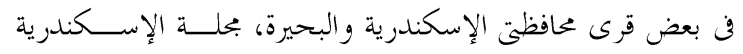

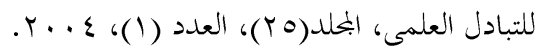
عبد المقصود، هججت محمد، الفجوة النوعية وتحسين فعاليسـة الإرشــاد

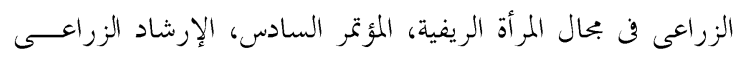

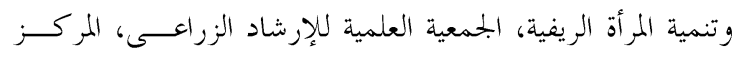

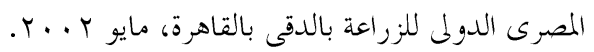




\title{
ABSTRACT \\ A Study of The Effect of Some Extension Methods As One of Variables Correlated with Rural Women in Making Participation Decisions Related to Some Animal and Plant Products in Some Villages of Behaira and Gharbia Governorates
}

\author{
Laila Tolba and Safaa Faheem
}

The main findings are:

- There is a lake of contribution degree in making marketing decisions, as $(38.3 \%)$ of the sample have a low degree of contribution, (41.1\%) have medium degree, while (20.6\%) only of the sample showed a high degree of contribution.

This research mainly aimed to study the effect of some extension methods upon contribution of rural women in making decisions related to some animal and agricultural products, through the following sub - goals:

- Study of some characteristics of the respondents.

- Identify contribution degree in making marketing decisions.

- Identify the main extension methods displayed for rural women.

- Study of the effect of some independent variables upon the participation degree in making marketing decisions.

- Identify the main problems that affect upon the participation in making marketing decisions

- And finally the proposed solutions from the point of view of the respondents.

Data were collected from a purposive sample consisted of 180 rural women from some villages in Behaira and Gharbia Governorates.

- The study founded that the main extension methods that displayed to the respondents to get the marketing knowledge and information are: visiting of the female agricultural agent to houses of rural women, meeting with the agricultural agent, directed rural T.V and Radio programs, demonstrations, visiting the developing projects, and finally the extension prints.

- The study founded a significant descending relation between the contribution degree in making marketing decisions and each of: displaying of some extension methods, information resources, age of the respondents and plant and animal products. 